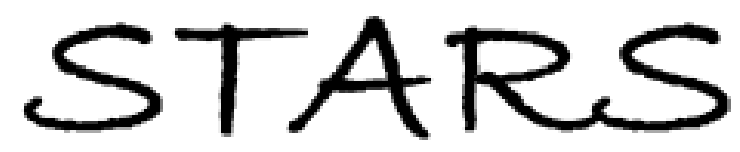

University of Central Florida

STARS

$1-1-2001$

\title{
The 1999 Marsokhod rover mission simulation at Silver Lake, California: Mission overview, data sets, and summary of results
}

C. R. Stoker

N. A. Cabrol

T. R. Roush

J. Moersch

J. Aubele

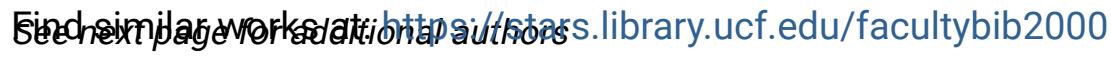

University of Central Florida Libraries http://library.ucf.edu

This Article is brought to you for free and open access by the Faculty Bibliography at STARS. It has been accepted for inclusion in Faculty Bibliography 2000 s by an authorized administrator of STARS. For more information, please contactSTARS@ucf.edu.

\section{Recommended Citation}

Stoker, C. R.; Cabrol, N. A.; Roush, T. R.; Moersch, J.; Aubele, J.; Barlow, N.; Bettis, E. A. III; Bishop, J.; Chapman, M.; Clifford, S.; Cockell, C.; Crumpler, L.; Craddock, R.; De Hon, R.; Fpster, T.; Gulick, V.; Grin, E.; Horton, K.; Hovde, G.; Johnson, J. R.; Lee, P. C.; Lemmon, M. T.; Marshall, J.; Newsom, H. E.; Ori, G. G.; Reagan, M.; Rice, J. W.; Ruff, S. W.; Schreiner, J.; Sims, M.; Smith, P. H.; Tanaka, K.; Thomas, H. J.; Thomas, G.; and Yingst, R. A., "The 1999 Marsokhod rover mission simulation at Silver Lake, California: Mission overview, data sets, and summary of results" (2001). Faculty Bibliography 2000s. 2965.

https://stars.library.ucf.edu/facultybib2000/2965

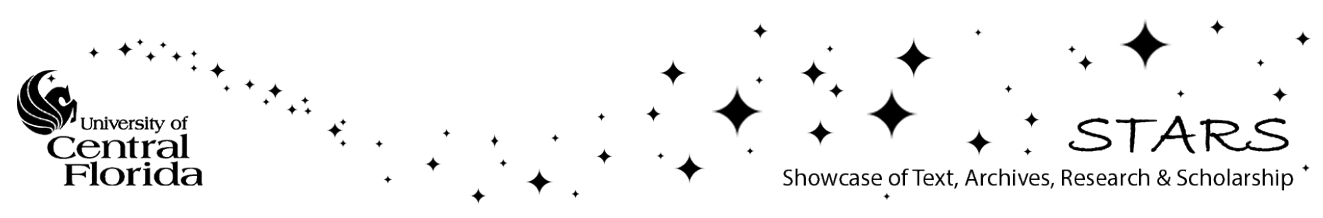




\section{Authors}

C. R. Stoker, N. A. Cabrol, T. R. Roush, J. Moersch, J. Aubele, N. Barlow, E. A. Bettis III, J. Bishop, M. Chapman, S. Clifford, C. Cockell, L. Crumpler, R. Craddock, R. De Hon, T. Fpster, V. Gulick, E. Grin, K. Horton, G. Hovde, J. R. Johnson, P. C. Lee, M. T. Lemmon, J. Marshall, H. E. Newsom, G. G. Ori, M. Reagan, J. W. Rice, S. W. Ruff, J. Schreiner, M. Sims, P. H. Smith, K. Tanaka, H. J. Thomas, G. Thomas, and R. A. Yingst 


\title{
The 1999 Marsokhod rover mission simulation at Silver Lake, California: Mission overview, data sets, and summary of results
}

\author{
C. R. Stoker, ${ }^{1}$ N. A. Cabrol, ${ }^{1}$ T. R. Roush, ${ }^{1}$ J. Moersch, ${ }^{2}$ J. Aubele, ${ }^{3}$ N. Barlow, ${ }^{4}$ \\ E. A. Bettis III, ${ }^{5}$ J. Bishop, ${ }^{1}$ M. Chapman, ${ }^{6}$ S. Clifford, ${ }^{7}$ C. Cockell, ${ }^{1}$ L. Crumpler, ${ }^{3}$ \\ R. Craddock, ${ }^{8}$ R. De Hon, ${ }^{9}$ T. Foster, ${ }^{5}$ V. Gulick, ${ }^{1}$ E. Grin, ${ }^{1}$ K. Horton, ${ }^{10}$ \\ G. Hovde, ${ }^{1}$ J. R. Johnson, ${ }^{6}$ P. C. Lee, ${ }^{1}$ M. T. Lemmon, ${ }^{11}$ J. Marshall, ${ }^{1}$ \\ H. E. Newsom, ${ }^{12}$ G. G. Ori, ${ }^{13}$ M. Reagan, ${ }^{5}$ J. W. Rice, ${ }^{11}$ S. W. Ruff, ${ }^{14}$ \\ J. Schreiner, ${ }^{1}$ M. Sims, ${ }^{1}$ P. H. Smith, ${ }^{11}$ K. Tanaka,${ }^{6}$ H. J. Thomas, ${ }^{1}$ \\ G. Thomas, ${ }^{15}$ and R. A. Yingst ${ }^{11}$
}

\begin{abstract}
We report on a field experiment held near Silver Lake playa in the Mojave Desert in February 1999 with the Marsokhod rover. The payload (Descent Imager, PanCam, Mini-TES, and Robotic Arm Camera), data volumes, and data transmission/receipt windows simulated those planned for the Mars Surveyor mission selected for 2001. A central mast with a pan and tilt platform at $150 \mathrm{~cm}$ height carried a high-resolution color stereo imager to simulate the PanCam and a visible/near-infrared fiberoptic spectrometer (operating range $0.35-2.5 \mu \mathrm{m}$ ). Monochrome stereo navigation cameras were mounted on the mast and the front and rear of the rover near the wheels. A field portable infrared spectroradiometer (operating range 8-14 $\mu \mathrm{m}$ ) simulated the Mini-TES. A Robotic Arm Camera, capable of close-up color imaging at $23 \mu \mathrm{m} / \mathrm{pixel}$ resolution, was used in conjunction with the excavation of a trench into the subsurface. The science team was also provided with simulated images from the Mars Descent Imager and orbital panchromatic and multispectral imaging of the site obtained with the French SPOT, airborne Thermal Infrared Mapping Spectrometer, and Landsat Thematic Mapper instruments. Commands sequences were programmed and sent daily to the rover, and data returned were limited to $40 \mathrm{Mbits}$ per communication cycle. During the simulated mission, 12 commands were uplinked to the rover, it traversed $\sim 90 \mathrm{~m}$, six sites were analyzed, 11 samples were collected for laboratory analysis, and over $5 \mathrm{Gbits}$ of data were collected. Twenty-two scientists, unfamiliar with the location of the field site, participated in the science mission from a variety of locations, accessing data via the World Wide Web. Remote science interpretations were compared with ground truth from the field and laboratory analysis of collected samples. Using this payload and mission approach, the science team synergistically interpreted orbital imaging and infrared spectroscopy, descent imaging, rover-based imaging, infrared spectroscopy, and microscopic imaging to deduce a consistent and largely correct interpretation of the geology, mineralogy, stratigraphy, and exobiology of the site. Use of imaging combined with infrared spectroscopy allowed source outcrops to be identified for local rocks on an alluvial fan. Different lithologies were distinguished both near the rover and at distances of hundreds of meters or more. Subtle differences such as a contact between dolomite and calcite were identified at a distance of $0.5 \mathrm{~km}$. A biomarker for endolithic microbiota, a plausible life form to be found on Mars, was successfully identified. Microscopic imaging of soils extracted from the surface and subsurface allowed the mineralogy and fluvial history of the trench site to be deduced. The scientific productivity of this simulation shows that this payload and mission approach has high science value and would contribute substantially to achieving the goals of Mars exploration.
\end{abstract}

\footnotetext{
${ }^{1}$ NASA Ames Research Center, Moffett Field, California.

${ }^{2}$ Department of Geological Sciences, University of Tennesee, Knoxville.

${ }^{3}$ New Mexico Museum of Natural History and Science, Albuquerque.

${ }^{4}$ Department of Physics, University of Central Florida, Orlando.

${ }^{5}$ Department of Geoscience, University of Iowa, Iowa City.

${ }^{6}$ United States Geological Survey, Flagstaff, Arizona.

Copyright 2001 by the American Geophysical Union.

Paper number 1999JE001178.

0148-0227/01/1999JE001178\$09.00
}

\footnotetext{
${ }^{7}$ Lunar and Planetary Institute, Houston, Texas.

${ }^{8}$ Smithsonian Institution, Washington, D. C.

${ }^{9}$ Department of Geosciences, University of Louisiana, Monroe.

${ }^{10}$ Hawaii Institute of Geophysics and Planetology, University of Hawaii at Manoa, Honolulu.

${ }^{11}$ Lunar and Planetary Laboratory, University of Arizona, Tucson.

${ }^{12}$ Department of Earth and Planetary Sciences, University of New Mexico, Albuquerque.

${ }^{13}$ Dipartimento di Scienze, Universita' d'Annunzio, Pescara, Italy.

${ }^{14}$ Department of Geology, Arizona State University, Tempe.

${ }^{15}$ Department of Industrial Engineering, University of Iowa, Iowa City.
} 


\section{Introduction: Background and Previous Work}

Rovers represent an important capability for Martian surface exploration. The Pathfinder mission first demonstrated the practical benefits of rovers on Mars [Golombek et al., 1999; Moore et al., 1999; Rover Team, 1997]. The Pathfinder Sojourner rover was small and carried a very limited science payload. Nevertheless, over the course of the mission the Sojourner rover traversed $\sim 90 \mathrm{~m}$, analyzing rocks and soils and performing material-properties experiments. The Mars Surveyor program is planning a series of rover missions designed for in situ exploration and the return of Martian samples to Earth. This program plans to employ capable rovers carrying sophisticated science payloads and collecting samples of interest and returning them to a sample return vehicle. Developing rovers with the desired capabilities will require critical issues to be addressed from technological, engineering, and scientific standpoints. The success of this program is closely tied to our ability to send adequate instrumentation to Mars and to develop rovers capable of carrying the required instrumentation that are robust enough to travel long distances and survive the exposure to the extreme Martian environment over a long period of time. The interaction between rover operations and science teams that must plan these activities is another crucial element. Methods must be found to involve scientists effectively in the daily planning process and keep science operations moving smoothly and efficiently over many months of operations.

Mission simulations using instrumented rovers in terrestrial field sites can provide the experience needed to evaluate instrumentation and design mission operations and science analysis methods critical to performing effective exploration of Mars [Committee on Lunar and Planetary Exploration (COM$P L E X), 1999]$. Mission simulations at field sites on the Earth have the advantage that they can be performed at low cost, they can involve a broad segment of the science community, and the performance of these teams and accuracy of their conclusions can be evaluated with ground truth from the field. A number of previous field experiments have been conducted to simulate the operational elements of Mars rover missions. The most relevant to the one reported on here involved science teams analyzing data collected by rovers deployed at Mars analog field sites. Field experiments along these lines have been performed using the Russian-developed Marsokhod rover [Greeley et al., 1994; Stoker, 1998; Christian et al., 1997], the Rocky rover developed at the Jet Propulsion Laboratory [Anvidson et al., 1998] and the Nomad rover developed by Carnegie Mellon University [Cabrol et al., this issue (a), this issue (b)]. The Marsokhod and Nomad experiments were blind tests in which field sites were studied using imaging systems carried on board the rover by science teams located in mission operations centers that were removed from the field location and had no prior knowledge of it. Field experiments using the Rocky rover [Arvidson et al., 1998] involved more complete and flight-like instrument complements but were not conducted in the blind, as the science team was located at the rover operations site. None of the previous experiments simulated realistic Mars mission command cycle time or data bandwidths.

The current experiment was designed to simulate the science data returned and operational environment of a Mars lander and rover mission originally selected for flight in 2001. Instruments used in the test simulated the PanCam and Mini-TES investigations from the Athena science payload [Squyres et al.,
1999] and the Robotic Arm and Robotic Arm Camera (RAC) from the Mars Volatiles and Climate Survey (MVACS) payload [Keller et al., 2001]. Instruments on the Athena payload were originally selected for a sample collection rover. The RAC and a Robotic Arm were also selected as a payload on the accompanying 2001 lander. Subsequently, the loss of the Mars Polar Lander and restructuring of the Surveyor program caused the cancellation of the 2001 landed mission. The Athena payload is now planned for the Mars Exploration Rover to be launched in 2003. However, at the time this experiment was performed, both the Athena rover and the RAC were on track for flight in 2001.

The purpose of the test was to evaluate the effectiveness of instrument payloads and science operations procedures in achieving science goals of the mission. Objectives of the experiment were (1) to evaluate the importance and effectiveness of imagery and spectroscopy from orbital, descent, and rover platforms in achieving science objectives; (2) to evaluate the additional information that can be learned by being able to dig below the surface and image subsurface materials at a microscopic scale; (3) to expose the science team to rover operations, thereby training them in the capabilities and limitations of this mission type, while getting their feedback for improving operational procedures; (4) to develop and evaluate protocols for and coordinating between a distributed science team and a rover team; and (5) to test algorithms and concepts for onboard science analysis.

The science goals of the simulated mission were based on those of the Mars Surveyor Program: understanding the relationship between geologic history, climate history, and possible life with the underlying theme of understanding the history of water. The science team was asked to document the geology, stratigraphy, mineralogy, morphology, and exobiology of the field site. In the case of exobiology the emphasis was on searching for samples that might contain either fossil evidence of life or living organisms such as evidence of bacterial forms that might plausibly be found on Mars. They were asked to use the orbital and descent data to develop hypotheses that could be tested using rover-based data, to characterize and identify rocks representative of the main geologic events at the site, to identify the geologic processes that have operated on materials at the site, to reconstruct the stratigraphic sequence of events at the site using rover observations, to identify samples having the highest possible chance of preserving evidence of life (past or present), and to select samples for return.

In the sections that follow, we first (section 2) describe the geologic context and rationale for selection of the test site. Next (section 3) we describe the rover and payload and auxiliary data sets used in the test. Section 4 describes the mission simulation organization and methodology and the data acquired. Section 5 summarizes the interpretations from the remote science team and compares their observations with ground truth. The results of the experiment are used to deduce recommendations for future rover missions in section 6 . Finally, section 7 summarizes the conclusions from the test.

\section{Field Test Site}

The regional geologic setting of the test site is given by Grin et al. [this issue]. The field test site is located near the shore of a dry playa called Silver Lake, located in the Mojave Desert northwest of the city of Baker, in central San Bernardino County, California. Figure 1 shows an air photograph of the field test site. Silver Lake $\left(26 \mathrm{~km}^{2}\right)$ is located in the Silurian 


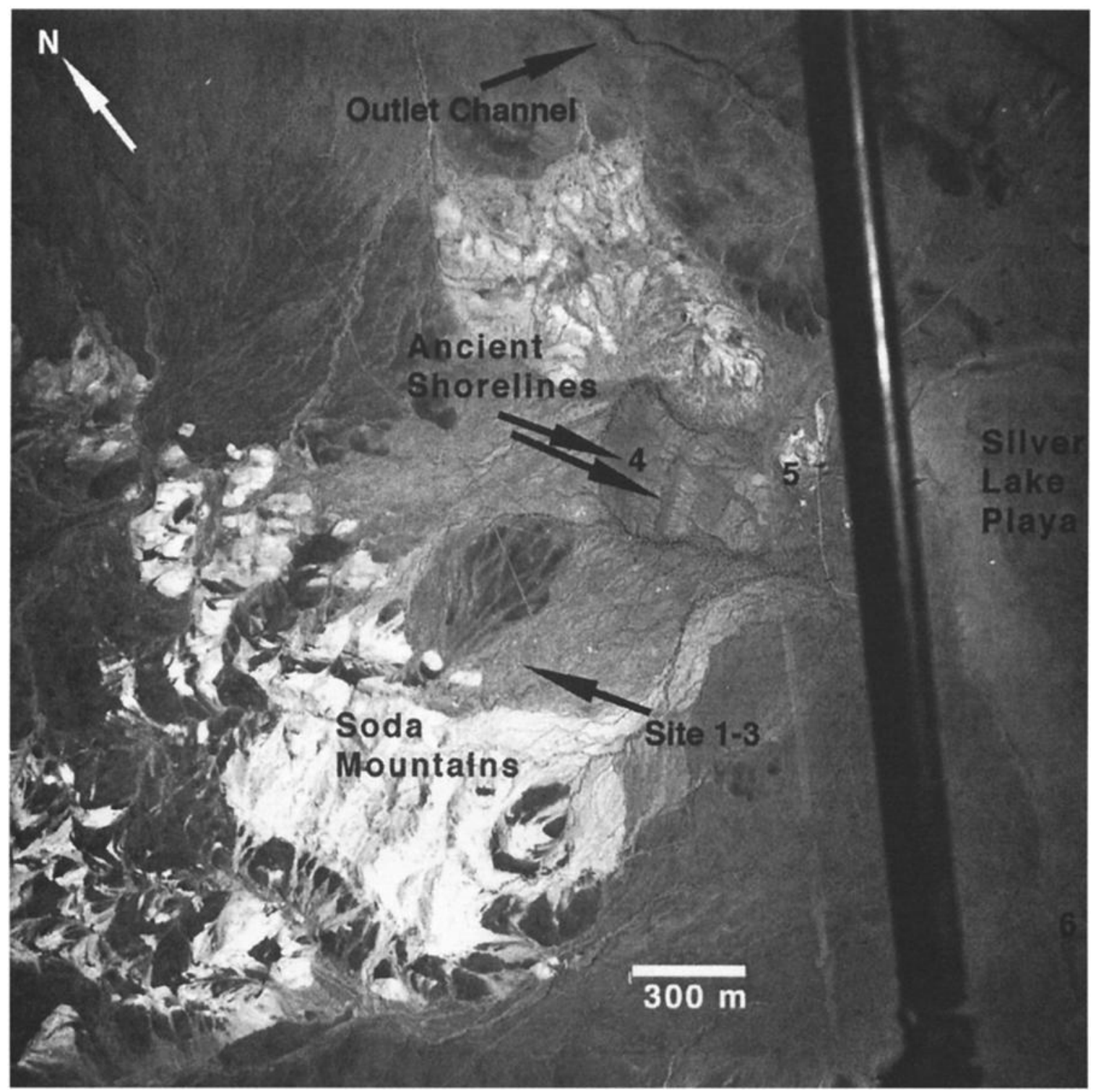

Figure 1. Aerial photograph of the field test site at $2.8 \mathrm{~m} /$ pixel resolution. Sites $1-6$ were explored during the test. The arrow in the top left points north. The scale bar in the bottom right is $300 \mathrm{~m}$. The Silver Lake playa is on the far right of the image. The positions of ancient shorelines and the Soda Mountains are shown. The dark foreground object occluding a portion of the right side of the image is aircraft structure.

Valley, situated between the Soda Mountains on the west and the Kingston Range on the east. The Silurian Valley forms the south/north extension of the Death Valley fault zone across the Mojave Desert. The sag of Silurian Valley illustrates the lowering of the Mojave block that underlies it. The lowering of the block was caused by the extensional faulting along the west coast. The tectonic extension and erosion have exhumed the lithology of formations at the site. Associated extensional faulting inland produced basin and range topography that characterizes the field test site.

The basement of the eastern Mojave block where the field test lies is composed of a Pretertiary complex of early Proterozoic amphibolites and quartzofeldspathic gneisses and schists overlain by Late Proterozoic and Paleozoic sedimentary rocks. Paleozoic dolomite marbles make up the bulk of the platform sediments atop the Precambrian basement in the field test area. These rocks are cut by Mesozoic granitic to dioritic intrusions [Burchfield and Davis, 1981].
Compressional tectonics dominated this region from Permian through Cretaceous time, although extensional faults associated with middle Cretaceous plutonism are found to the southwest of the field test site [Walker and Wardlaw, 1989]. In the Soda Mountains area, much of this magmatism occurred during the Cretaceous [Walker and Wardlaw, 1989], whereas much of the magmatism in the Avawatz Mountains to the north is Jurassic in age [Spencer, 1990].

The Avawatz Mountains underwent extension between 21 and 12 Ma [Spencer, 1990]. Thus it is likely that the extension in the northern Soda Mountains occurred at about this same time. This extension may have been caused by upwelling of mantle, possibly in association with the opening of a "subduction window" due to the formation of the San Andreas transform fault between the Pacific and North American plates [Glazner and Supplee, 1982].

Silver Lake and the nearby surroundings record periods of lacustrine activity leading to formation of the Silver Lake playa 
and older shorelines that are manifested at the site. The source of water to Silver Lake is the Mojave River, which, at present, flows only at times of heavy flooding. Water levels that formed paleoshorelines (Figure 1, Site 4) occurred during the late Pleistocene, when a series of lakes and spillways were formed along the course of the Mojave River, including Lake Mojave, which consisted of two pluvial age lakes located in an elongate basin that now contains Silver Lake playa and Soda Lake playa to the south [Thomson, 1929]. Lake Mojave filled and then spilled out to the north, where an outlet channel was carved (Figure 1). Ore and Waren [1971] have constructed a chronology of events that accounts for the series of paleoshorelines visible at the site. At 14.5 thousand years ago, water overflowed the outlet channel located at the northeastern margin of the lake. A second wet period lasted from 13.7 to 12 thousand years ago; extensive shorelines were formed at the same elevation as the outflow channel, and less extensive ones formed at a slightly lower lake level. A third high-water period at 11-9 thousand years ago resulted in downcutting of the outflow channel and shorelines formed at an even lower elevation. A lake formed in the basin from 8.5 to 7.5 thousand years ago but did not overflow the outlet channel. Extensive drying occurred after 7.5 thousand years ago. Episodically, significant water levels have occurred in Silver Lake in modern times.

The regional morphology of the landing site (Figure 1, Sites 1-3) was an alluvial apron that can be considered as a grab bag of samples from the local basement transported by episodic flows. Arroyos cut through this apron and drain into a playa that was once a pluvial lake. The surface of the apron has a variably developed desert pavement that is dissected by numerous sandy washes, gullies, and arroyos. The pavement and the sandy washes are trafficable by a rover. Hills emerging from the pediment to the west and north of the landing site consisted in large measure of light colored rocks that are identifiable on descent images as locations likely to consist of carbonate lithologies.

The diversity of rocks in the accessible parts of the pediment and the exposure of the outcrops in the mountain block of the test site were sufficient to reconstruct a fairly accurate geological and paleoenvironmental history of the site. The characterization of current and past environments of landing sites is a key element of Martian exploration. The site was also relevant to exobiology because of the presence of metamorphosed biologically deposited carbonates, evidence of fluvial activity (arroyos), and the close paleolake shorelines.

The Silver Lake test site was selected because it provided a good analogy to Martian environments that are relevant to the Surveyor Program objectives, i.e., addressing questions of water evolution, geologic history, climate history, and evidence for life. There is mounting evidence that water was present at the surface of Mars early in its history and ponding took place in both topographic lows and impact craters [Grin and Cabrol, 1997; Malin et al., 1998; Smith et al., 1997; Basilevski et al., 1999; Bridges et al., 1999; Chapman and Kargel, 1999; Jakosky, 1999; Smith et al., 1999; Golombek, 1999; Golombek et al., 1999; Greeley et al., 1999; Ward et al., 1999; McEwen et al., 1999; Hartmann et al., 1999; Malin and Car, 1999; Thomas et al., 1999; Cabrol and Grin, 1999]. Silver Lake thus presents an analog for climatic evolution (from wet to dry) on Mars. The Silver Lake region also represents an example of cascading lakes and spillways, which may reflect the formative processes of Martian paleolakes, as proposed by Scott et al. [1991, 1992, 1995] and Rice et al. [1999]. Also, with its different depositional environments, from gravel bars in alluvial fans to a dry lake bed, it provided the opportunity to face diverse trafficability challenges, from rough to smooth surfaces with varied slopes. The local morphology at the landing site was a good analog to a grab bag site located at the debouchment of a catastrophic flood or river channel. The alluvial fan displays a large variety of rocks extracted from the mountain ranges to the west and transported by small washes. Compared to the Viking and Pathfinder landing sites, the "landing site" (Figure 1, Sites 1-3) has a higher rock abundance and a lack of loose fines. Because of its proximity to a large peak, the site would probably be considered dangerous from the viewpoint of landing site safety. However, it would represent a high-priority science target for a Martian rover traverse because of the potential science outcome in terms of climate, hydrogeology, and exobiology. Finally, the search for evidence of life, both fossil and living, could be successful at the test site because of the presence of ancient shells and of microorganisms commonly found in fractures in many of the carbonate rocks at the site and/or at the contact between the rocks and the soil. These organisms could be recognized by the presence of a green stain visible under the surface when certain rocks were fractured or on the underside of semitransparent rocks. In the latter case the green stain was visible when these rocks were overturned, exposing the part of the rock in contact with the soil.

\section{Mission Payload}

\subsection{Marsokhod Rover}

The Marsokhod is a planetary surface rover originally developed for Mars flight missions by the Mobile Vehicle Engineering Institute (VNII Transmash) in Russia. It has been previously described by Christian et al. [1997] and Stoker [1998]; here we briefly review its capabilities as used in this experiment. Figure 2 shows the Marsokhod rover, and Table 1 lists its main features. The Marsokhod chassis consists of three pairs of independently driven titanium wheels, joined together by a three degree of freedom passively articulated frame. The amplifiers, motors, and batteries are mounted inside the wheels to produce a very low center of gravity. Mounted above each wheel segment is a rigid pallet for mounting additional equipment. The front pallet supports the arm and its electronics. The middle pallet supports a mast carrying a pan and tilt platform for pointing cameras and other instruments. The rear pallet houses the rest of the electronics and computers. Batteries can power the rover for up to 6 hours without recharging. Solar panels mounted on the rover provide the primary power for charging the batteries, or they can be charged via a small portable generator.

The rover was navigated using one of two modes. In the first mode, called "dead reckoning," the rover was simply commanded to turn to a given heading relative to the current heading and then move a certain distance in that direction. The second navigational mode used a vision-based tracking system [Wettergreen et al., 1997] to autonomously drive the robot to a natural feature (e.g., a rock outcropping) designated by the operator. The target object is kept in view by the rover's mast camera as the rover moves toward it.

Sequences of commands were sent to instruct the rover to perform tasks. A rover command was assembled using a Command User Interface [Blackmon et al., 1999] that allowed the rover team to interactively build a contingent sequence of activities to meet the desired goals. A high-level sequencing 

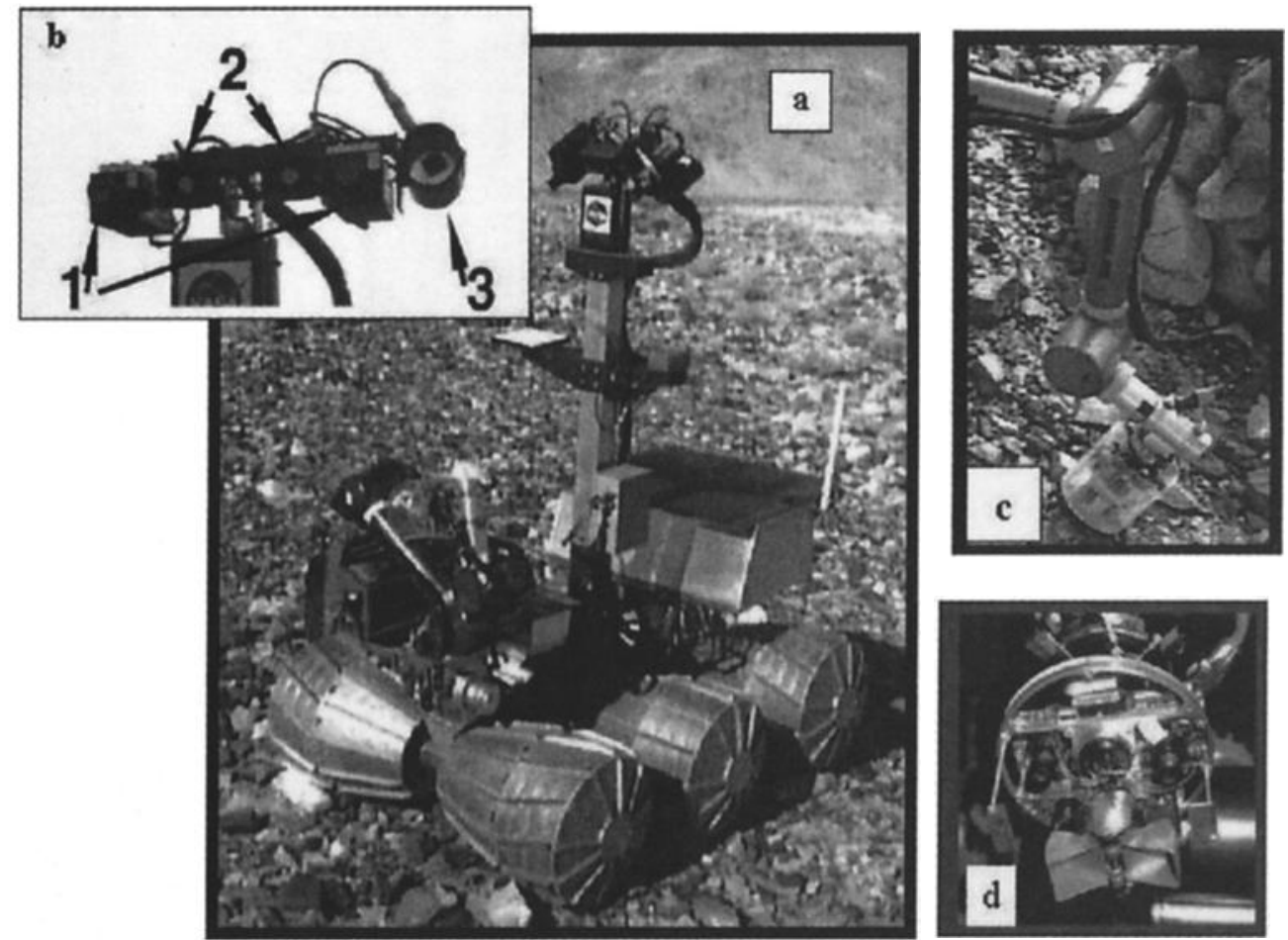

Figure 2. (a) The Marsokhod rover shown along with (b) a close-up of the pan and tilt platform holding (1) the color stereo cameras, (2) the navigation cameras, and (3) the entrance aperture of the VNIR spectrometer. A 5 degree of freedom (DOF) arm with $1 \mathrm{~m}$ maximum reach is mounted on Marsokhod's front pallet (Figure 2c). A rotary carousel end effector is mounted on the wrist joint, which holds up to three instruments and a sample scoop (Figure 2d). Images from a camera mounted in this carousel were used to verify arm placement.

language [Bresina et al., 1999], demonstrated for the first time on this field test, provided the ability to place conditional branches into the sequence that are dependent on real-time events on board the rover. Following construction of sequences using this high-level language, the sequence of tasks would be decomposed into a set of low-level rover task commands that were uplinked to the rover and understood by an executive program running on the onboard computer. The executive then can take the list of commands, prioritize them, and add and omit tasks depending on the status of the sensors and the success/failure of the previously executed tasks.

A mission operations facility at NASA Ames (Moffett Field, California) hosted mission planning, rover control, and science operations. A small motor home served as a remote command post at the field site, housing the field team and support equip-

Table 1. Marsokhod Characteristics

\begin{tabular}{lc}
\hline \multicolumn{1}{c}{ Parameter } & Value \\
\hline Length, cm & 150 \\
Width, cm & 100 \\
Height (at center mast), cm & 150 \\
Number of wheels & 6 \\
Wheel diameter, cm & 35 \\
Mass loaded with payload and electronics, kg & 120 \\
Maximum obstacle traversed, cm & 35 \\
Speed, m/s & 0.2 \\
Open terrain & 0.06 \\
Extremely rocky terrain & $45^{\circ}$ \\
Maximum ascent/descent angle (in loose soil), deg & \\
\hline
\end{tabular}

ment during mission operations. Rover data were transmitted from the onboard computer to the motor home using a radio ethernet, where they were merged with data from offboard instruments and transmitted to mission control at NASA Ames using a portable satellite transmission station operating at a bandwidth of $128 \mathrm{kbits} / \mathrm{s}$.

\subsection{Science Instrumentation}

Data sources for the science team fell into three categories: (1) simulations of orbital data, (2) instruments on board the rover, and (3) instruments that simulate upcoming mission capabilities but, for a variety of reasons, were not mounted on the rover and therefore were simulated. Table 2 lists the instrument complement used for this field experiment.

3.2.1. Simulated orbital data. Simulated orbital data were provided to the science team several months before the start of the science mission. Data provided included an orbital image of the site acquired by the SPOT imager at $10 \mathrm{~m} /$ pixel resolution (Plate 1a), a pseudocolor image of the site produced from the airborne Thermal Infrared Multispectral Scanner (TIMS) (Plate 1b), and a set of multispectral Landsat Thematic Mapper images (six wavelengths from 0.45 to $2.35 \mu \mathrm{m}$ and one centered at $11.45 \mu \mathrm{m}$ ) (Plates $1 \mathrm{c}$ and $1 \mathrm{~d}$ ). Plate $1 \mathrm{~b}$ shows the TIMS image with bands 5, 3, and 1 displayed as red, green, and blue, respectively, to enhance discrimination of various compositional units in the scene [e.g., Kahle and Goetz, 1983; Gillespie et al., 1984; Sabine et al., 1994]. In this color scheme, bright red indicates high quartz content, bright green indicates carbonate, and cyan indicates mafic or quartz-poor material. Plate $1 \mathrm{c}$ shows an image of the test site made using 
Table 2. Instrument Summary

\begin{tabular}{|c|c|c|c|}
\hline Imagers & Pixels & $\begin{array}{c}\text { FOV } \\
\text { deg }\end{array}$ & Resolution \\
\hline Descent Imager (simulated) & $1000 \times 1000$ & 66 & $0.01-3 \mathrm{~m} / \mathrm{pixel}$ \\
\hline \multicolumn{4}{|l|}{ Cameras } \\
\hline Color stereo on mast & $480 \times 640$ & $8 \times 11$ & $0.3 \mathrm{mrad}$ \\
\hline Stereo navigation on mast & $480 \times 640$ & $25 \times 33$ & $1 \mathrm{mrad}$ \\
\hline Front and rear bumper stereo navigation cameras & $480 \times 640$ & $25 \times 33$ & $1 \mathrm{mrad}$ \\
\hline \multicolumn{4}{|l|}{ Manipulator arm } \\
\hline Wrist camera & $480 \times 640$ & $28 \times 36$ & $\begin{array}{l}1 \mathrm{mrad}, 0.1 \mathrm{~mm} \\
\text { close position }\end{array}$ \\
\hline \multirow[t]{2}{*}{ Robotic Arm Camera (offboard) } & $256 \times 512$ & $30 \times 59$ & $\begin{array}{l}2 \mathrm{mrad}, 23 \mu \mathrm{m} \\
\text { close position }\end{array}$ \\
\hline & $\begin{array}{l}\text { Wavelength } \\
\text { Range, } \\
\mu \mathrm{m}\end{array}$ & $\begin{array}{l}\text { FOV } \\
\text { deg }\end{array}$ & $\begin{array}{l}\text { Spectral } \\
\text { Resolution }\end{array}$ \\
\hline $\begin{array}{l}\text { Visible/near-infrared-spectrometer on mast } \\
\text { Midinfrared spectrometer (offboard) }\end{array}$ & $\begin{array}{c}0.35-2.5 \\
8-14\end{array}$ & $\begin{array}{l}1 \\
0.86\end{array}$ & $\begin{array}{l}10^{-9} \mathrm{~m} \\
6 \mathrm{~cm}^{-1}\end{array}$ \\
\hline
\end{tabular}

${ }^{\text {a}}$ FOV, field of view.

the ratio of Thematic Mapper data in bands 2 and 4 (560/830 $\mathrm{nm})$. In this scheme, carbonates are dark and mafic and/or varnished rocks are bright. Plate $1 \mathrm{~d}$ shows a pseudocolor image of the test site, also made with Thematic Mapper band ratios. In this color scheme, clays or carbonates are red, and mafic rocks and iron oxides are blue-green. Also provided was an image of the site at $2.8 \mathrm{~m} /$ pixel resolution, comparable to the best resolution images obtained by the Mars Orbiter Camera on the Mars Global Surveyor [Malin et al., 1992, 1998]. Figure 1 shows this image.

3.2.2. Simulated descent imaging. Previous rover field experiments [Greeley et al., 1994; Stoker, 1998; Anvidson et al., 1998] have shown that aerial imaging support of rover operations is crucial to mission success. Aerial data are used in conjunction with orbital imaging to understand the geologic context of the landing site and to plan rover traverses to achieve the science goals of the mission. Descent Imagers were selected for flight on the Mars Polar Lander (1999) and the 2001 Surveyor lander.

Images were obtained to simulate data from the Mars Descent Imager (MARDI) experiment as planned for the 2001 lander mission. The MARDI has a circular field of view (FOV) of $66^{\circ}$ and images to a charge-coupled device (CCD) with $1000 \times 1000$ pixels and effective resolution of $1.3 \mathrm{mrad} / \mathrm{pixel}$. Between the time of parachute deployment (altitude $6170 \mathrm{~m}$ ) and cutaway, the descending spacecraft travels cross-range. Below $500 \mathrm{~m}$ the spacecraft descends straight down using descent engines. Eight images are acquired at altitudes ranging from $6170 \mathrm{~m}$ to the ground.

Simulated descent images were obtained from a helicopter using a Hasselblad camera equipped with a $41 \mathrm{~mm}$, F5.6 lens $\left(67^{\circ}\right.$ FOV ) using TRI-X ISO 400 film. Images were obtained at 1000 local solar time on June 3, 1998. Image positions simulated a spacecraft entry from the NE direction with a mean wind speed of $15 \mathrm{~m} / \mathrm{s}$ providing cross-range motion. The images were scanned to digital format and then subsampled to achieve the $1000 \times 1000$ pixel resolution of the MARDI. Because the images from the upper part of the descent do not have resolution better than can be acquired from orbit, descent images were taken at elevations between $2000 \mathrm{~m}$ and the ground. Table 3 shows the parameters associated with the images provided to the science team. Figure 3 shows descent images 3 and 4.

3.2.3. Rover-mounted imaging system. The imaging system on board Marsokhod consisted of cameras designated for science and navigational purposes. Table 4 lists the characteristics of the cameras. The PanCam Simulator (PCS), a color stereo camera mounted on a pan and tilt platform on the central mast (Figure 2), simulated the PanCam camera of the Athena payload [Squyres et al., 1999]. The PCS consists of a pair of color cameras, each with a three-CCD chip, one for each primary color (red, green, and blue). A stereo jig allowed the two color cameras to be precisely aligned in azimuth, elevation, and vergence. The cameras mimic the vision characteristics of the human eye in that they have $0.3 \mathrm{mrad}$ resolution, comparable to the foveal region of the human eye, and they are located at $150 \mathrm{~cm}$ above the ground. In addition, there were six navigation cameras arranged as three stereo pairs: one mounted on the pan and tilt platform on the mast and the other two mounted on the front and rear pallets and used for hazard avoidance. The manipulator arm also included a monochrome camera used for close-up imaging of science targets.

3.2.4. Visible/near-infrared spectrometer. A visible/nearinfrared (VNIR) spectrometer, measuring reflected solar energy over the $0.35-2.5 \mu \mathrm{m}$ wavelength domain, was used in conjunction with the Marsokhod rover. The device was a fiberoptic spectrometer, whose characteristics are provided in Table 5. A more detailed description of the device and its field operation is provided by Johnson et al. [this issue]. A telescope providing light input to the spectrometer was mounted on the Marsokhod pan and tilt platform and was optically aligned with the left camera of the PCS. The spectrometer required instrument proprietary software controlled by a laptop computer, making it incapable of being interfaced with the central Marsokhod computer. Field reflectance measurements were collected in two different modes. One mode used the telescope to obtain data under natural lighting conditions, which produced relative reflectance measurements. In this mode the spectrometer acted as a proxy for the Mars Surveyor Athena rover Mini-TES instrument (albeit working at different wavelengths), which will also be bore-sighted to the Athena PanCam stereo camera [Squyres et al., 1999; Morris et al., 1998]. In 


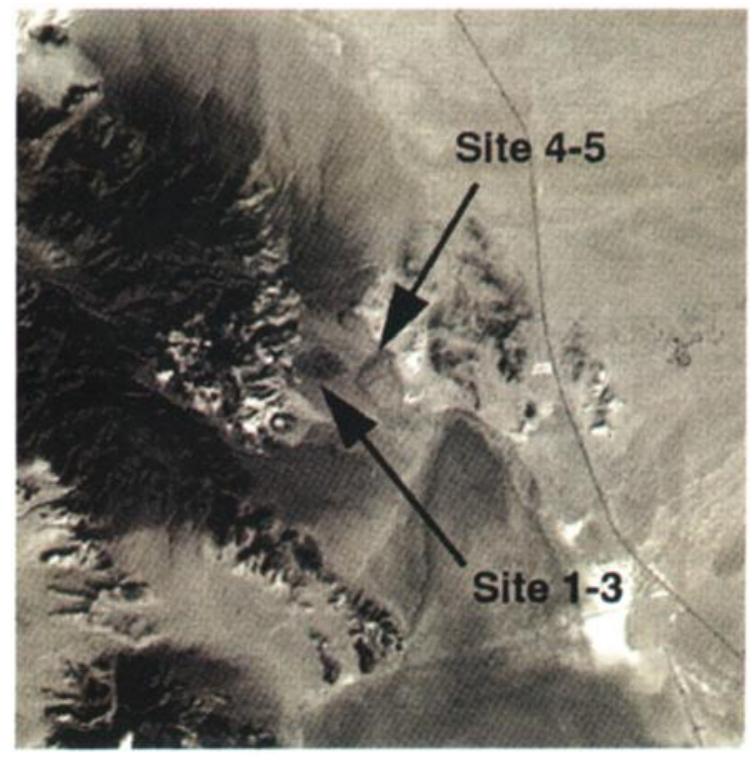

a

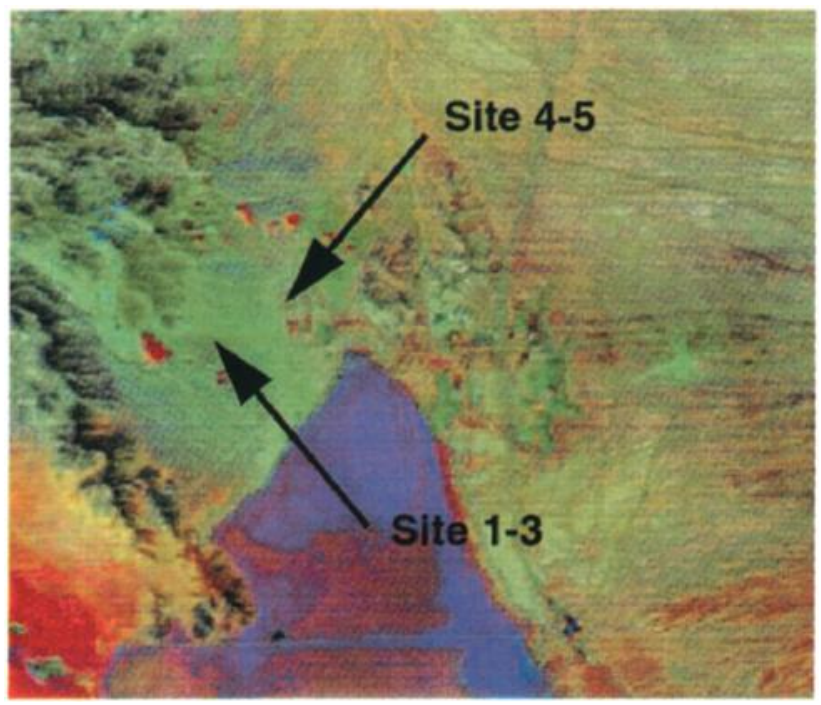

b

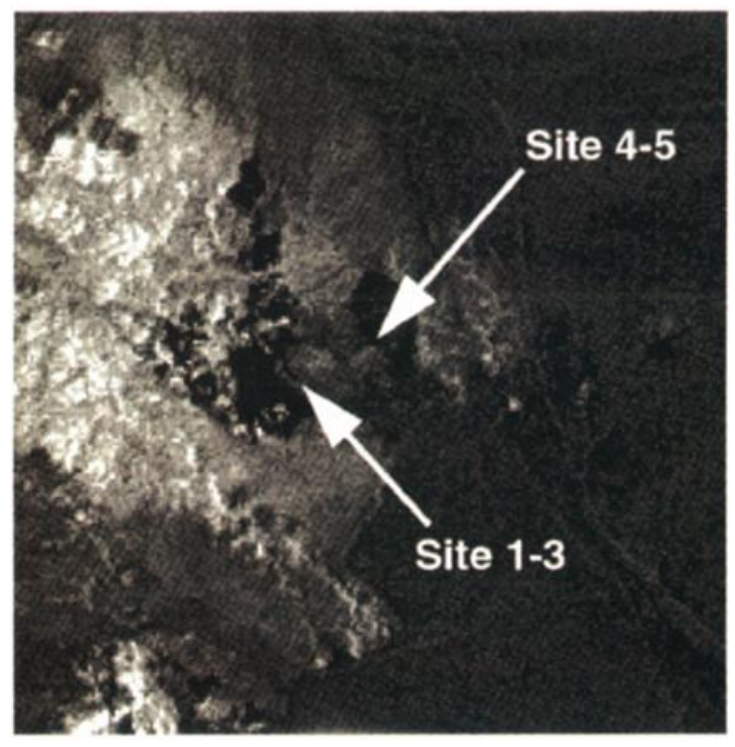

c

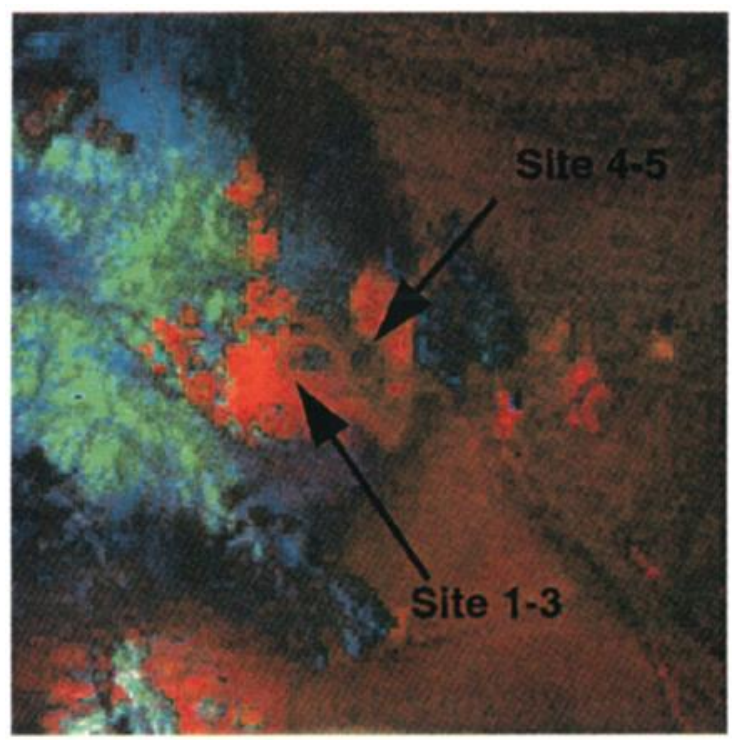

d

Plate 1. (a) SPOT panchromatic image $(510-730 \mathrm{~nm})$ of test site $(10 \mathrm{~m} /$ pixel) showing location of landing site (Sites 1-3) and paleoshorelines (Sites 4-5). Scene 545-279 acquired November 4, 1990. (b) Pseudocolor image of field test area derived from Thermal Infrared Multispectral Scanner images where band 5 (10.2-11.2 $\mu \mathrm{m})$ is red, band $3(9.0-9.4 \mu \mathrm{m})$ is green, and band $1(8.2-8.6 \mu \mathrm{m})$ is blue. (c) Ratio between two channels of Landsat Thermal Mapper (TM) data (560/830 nm). (d) Color composit of Landsat TM band ratios: red is $1650 / 2210 \mathrm{~nm}$; green is $660 / 485 \mathrm{~nm}$; and blue is $560 / 830 \mathrm{~nm}$. See text for interpretation of color schemes. Figure adapted from Johnson et al. [this issue]. All data are courtesy R. Arvidson.

the second mode the fiber optic input to the spectrometer was interfaced with an artificial light source placed directly over the sample, which drastically reduced the significant influence from reflected irradiance or atmospheric interference. Spectra obtained using artificial illumination most closely approximate an absolute measurement of the sample reflectance.

In addition to providing compositional information, an objective of the VNIR spectrometer experiment was to test the use of autonomous spectral recognition algorithms [see Gazis and Roush, this issue]. All spectra were analyzed for the presence of carbonate minerals using an algorithm on board the spectrometer's controlling laptop.
3.2.5. Thermal infrared spectrometer. A thermal infrared (TIR) spectrometer was used in the field test to simulate the Mini-TES on the Athena payload [Squyres et al., 1999]. However, no small field-portable thermal infrared spectrometer was available to be interfaced with the rover, so this capability was simulated off board using the instrument described below. A more detailed description of the instrument and its field operation is given by Johnson et al. [this issue]. Figure 4 shows the instrument being operated in the field, and Table 6 lists its characteristics.

The TIR instrument is a portable, battery-powered Fourier transform infrared (FTIR) spectroradiometer (Designs and 
Table 3. Simulated Descent Image Data

\begin{tabular}{cccccc}
\hline Image & $\begin{array}{c}\text { Distance } \\
\text { North, } \\
\mathrm{m}\end{array}$ & $\begin{array}{c}\text { Distance } \\
\text { East, } \\
\mathrm{m}\end{array}$ & $\begin{array}{c}\text { Altitude, } \\
\mathrm{m}\end{array}$ & $\begin{array}{c}\text { Footprint, } \\
\mathrm{m}\end{array}$ & $\begin{array}{c}\text { Resolution, } \\
\mathrm{m} / \text { pixel }\end{array}$ \\
\hline 1 & 326 & 99 & 1888.00 & 2790 & 2.8 \\
2 & 303 & 123 & 1541 & 2330 & 2.3 \\
3 & 148 & 88 & 921 & 1300 & 1.3 \\
4 & 25 & -53 & 228 & 300 & 0.30 \\
5 & -1 & -4 & 43 & 50 & 0.05 \\
6 & 23 & 12 & 11 & 10 & 0.01 \\
\hline
\end{tabular}

${ }^{a}$ Distance is from landing site.

Prototypes $\left.^{\mathrm{TM}}\right)$ that operates in the 8-14 $\mu \mathrm{m}\left(715-1250 \mathrm{~cm}^{-1}\right)$ wavelength range at a resolution of $6 \mathrm{~cm}^{-1}$ [Korb et al., 1996; Hook and Kahle, 1996; Crowley and Hook, 1996; Horton et al., 1998]. The instrument consists of an optical head housed in a hard case that provides temperature stabilization via a thermoelectric cooler, a small cassegrain reflector foreoptic, and a data collection/instrument control laptop computer. The instrument, a fairly large apparatus (Figure 4), was operated independently of the rover. The foreoptic and optical head were bolted to a pan/tilt platform on a tripod, which was placed at a fixed offset position next to the rover for data collection. The laptop computer was mounted in an aluminum briefcase, connected to the optical head by a $5 \mathrm{~m}$ electronic cable. The foreoptic gave the instrument an instantaneous FOV (IFOV) of $15 \mathrm{mrad}$ (full width at half maximum (FWHM)), or $15 \mathrm{~cm}$ at a range of $10 \mathrm{~m}$.

Field operations and commanding of the TIR instrument pointing were accomplished as follows. The science team annotated PCS and navigation camera images to indicate the desired target and provided digital files of these, along with a written description of the desired target, to the field team. The field team acquired the spectra and calibrated them in the field before transmittal back to the science team. Production of a calibrated radiance spectrum involved getting spectra of calibration targets as well as the desired spectral targets. The details of the calibration procedure are discussed by Johnson et al. [this issue]. In order to minimize disruption of other rover operations and contamination of the natural scene by calibration boards, etc., data acquisition took place after the rover completed all of its activities at a given stop. Acquiring TIR spectra was laborious and time consuming for the field team, so only a limited number of TIR spectra could be acquired during the experiment. The science team was instructed to prioritize their targets to allow for possible insufficient time to complete all requests.

3.2.6. Robotic Arm Camera. The Robotic Arm Camera (RAC) [Keller et al., 2001] was selected for flight by the Mars Surveyor Program for the 1998-launched Mars Polar Lander mission and for the lander selected for 2001. An engineering model of this camera in the 2001 lander configuration was used
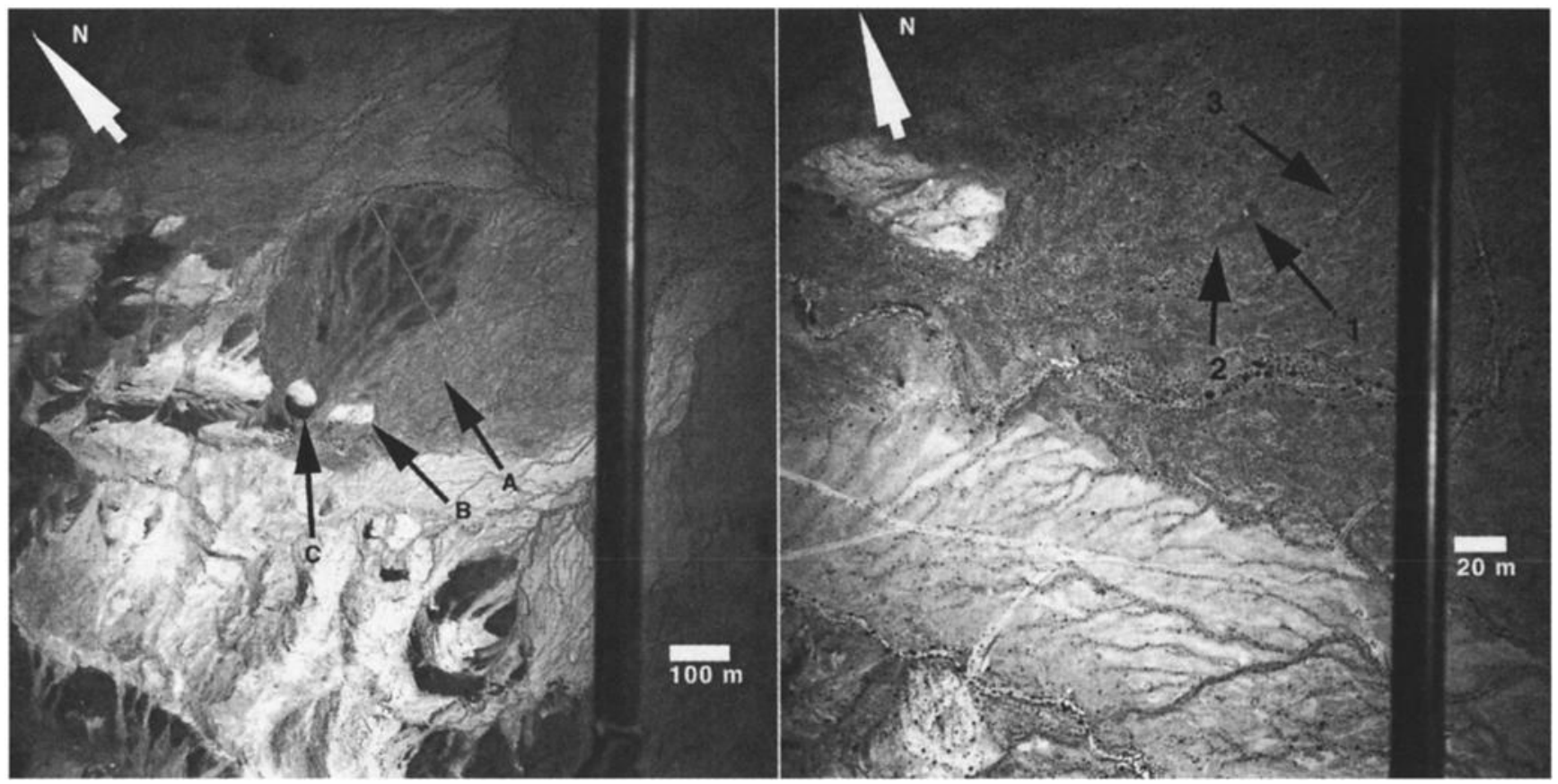

(a)

Figure 3. (a) Descent image $3,1.3 \mathrm{~m} /$ pixel resolution. The arrow in the top left points north. The black arrows point to the landing site (A), White Rock (B), and Acorn Hill (C). The white scale bar (bottom right) is $100 \mathrm{~m}$. (b) Descent image 4, $0.3 \mathrm{~m}$ /pixel resolution. Black arrows point to rover stops $1-3$. The white scale bar (bottom right) is $20 \mathrm{~m}$. The dark foreground object in both images is aircraft landing gear structure. 
for this experiment. Table 7 summarizes the characteristics of the RAC. The RAC is mounted near the wrist joint on the forearm of the Robotic Arm, which is used to point the camera. The RAC images to a CCD with $512 \times 256$ pixels. The far-focal pixel scale is $1.85 \mathrm{mrad} /$ pixel for a field of view of $50^{\circ}$ (azimuth) $\times 26^{\circ}$ (elevation). A focusing mechanism and $f / 11.2$ lens allow the camera to be focused from $11 \mathrm{~mm}$ to infinity. The near-focal $(11 \mathrm{~mm})$ pixel scale is $0.94 \mathrm{mrad} / \mathrm{pixel}$, so, at nearest focus, the camera can resolve $23 \mu \mathrm{m} /$ pixel. This highest resolution can be obtained only by imaging samples held in the sample scoop. Color images are obtained by illumination via red, green, and blue light-emitting diodes (LEDs) positioned next to the entrance aperature [see Yingst et al., this issue, Plate 1]. The data are read as 12 bits/pixel, resulting in an uncompressed data volume of 1.6 Mbits per image.

Figure 5 shows the RAC instrument setup used in the field. The action of the Robotic Arm was simulated by constructing a model of the forearm component mounted to a telescope tripod. The forearm model had an elbow joint capable of azimuth and elevation motion and a wrist joint with a scoop attached. For panoramic imaging the tripod was placed on a box, and the rotation of the camera about the tripod simulated the rotation of the arm at the shoulder with the shoulder vertical and the elbow pointed near or below the horizon. For trench imaging the arm was not well simulated, but a combination of translation of the tripod and rotation of the arm was used to aim the camera. The field team was able to place the camera within the trench for close-up imaging of trench walls. Microscopic images of samples were obtained by placing them in the scoop.

\section{Science Mission}

\subsection{Science Mission Organization}

The science mission simulation took place February 8-20, 1999. The field experiment was divided into three major phases. Phases 1 and 2 focused on characterizing the site using rover imaging and spectrascopy. During phase 1 (February 8-10) most of the science team was located at the NASA Ames mission operations center. During phase 2 (February 12-17) the science team had returned to their home institutions and continued mission planning by means of daily teleconferences with each other and the operations team located at NASA Ames. Phase 3 (February 19-20) focused on analysis of the subsurface using the RAC in association with other instruments. The RAC science team, a new group who had not been involved in phases 1 or 2 , analyzed data from this investigation. The science team from phases 1 and 2 followed the action and included the data obtained during phase 3 in their analysis. Ground truth for the science team's interpretations was provided by a geologist in the field who recorded extensive field observations of all the science targets and collected samples [Grin et al., this issue]. The samples returned were later subjected to standard petrographic analysis from a commercial laboratory. The science team was not provided with this ground truth until after the first drafts of papers describing their results were submitted for review. After this they compared their results with the ground truth to help them understand what had been overlooked or misinterpreted.

The organizational structure and communication flow used during the mission operation is shown in Figure 6. The mission scenario, team structure, and communication flow were organized by a mission manager who directed the science team activities and coordinated between the science, rover, and field teams as necessary. The science team was divided into four subgroups: (1) geomorphology and geology, (2) mineralogy and spectroscopy, (3) exobiology, and (4) RAC. Each day, a science team member was selected to act as science team leader for the day's operation and was responsible for organizing the science team's activities for that day, facilitating the planning for the next set of rover commands, and coordinating intrateam communication. Rotating the team leader assignments did not adversely affect mission continuity or program balance, and it helped to train all members of the science team in how to best accomplish mission objectives. Science teams were required to summarize observations and interpretations daily and assigned a confidence level (low to high) to interpretations. Interpretations were reviewed daily as new data were received.

Each day, the science team prepared a written request with the next set of operations and data acquisition to be performed, supported by pictures outlining desired science activities. This was especially important since some of the data, such as the TIR spectra and RAC images, were taken by field personnel who had to interpret a written request from the science team. For example, if the instruction was to collect a particular sample, the science team was to provide an image identifying the sample to be collected along with a context image of the general area where the sample was located. It was important to organize the data request so that the highestpriority activities occurred first because the commands often took longer than expected to perform. In addition to this written request, the science team explained their desires to a person assigned to interface between the science and the rover team who then helped the sequence planner to interpret the science request and make priority decisions when mission constraints meant that all the activities requested could not be achieved. The sequence planner implemented a sequence of commands to the rover to execute the request.

\subsection{Data Access}

After receipt at Ames, data were posted to a public World Wide Web site, where the science team could readily access them. All image files were posted, and, where panoramas were acquired, the image mosaics were built digitally and posted as well. In addition to the mosaics, various derived products were routinely provided to the science team within a few hours of receipt of data. Mosaics were set up with a "clickable map" interface that allowed the user to click on a feature of interest in the mosaic and access, via a hyperlink, the original image of the selected area. Stereo images and mosaics were processed into stereo anaglyphs and posted to the Web site. Threedimensional terrain models were built from stereo images using the Ames Stereo Pipeline [Stoker et al., 1999], coregistered with the images, and displayed to the science team using an interactive Virtual Reality interface. Versions of these models were also posted to the Web that could be viewed using QuickTime Virtual Reality.

The science team made extensive use of Postdoc(C), a Webbased collaboration capability developed by the Advanced Collaboration Environments group at NASA Ames Research Center, to share data products they produced, image analysis reports, geologic maps, and interpretations of data with the other science team members. Requests for rover data were also placed there for review before providing them to the rover team. The science team could upload and download docu- 
Table 4. Characteristics of Cameras Mounted on Marsokhod

\begin{tabular}{|c|c|c|c|c|}
\hline & $\mathrm{PCS}^{\mathrm{a}}$ & $\begin{array}{c}\text { Navigation } \\
\text { Cameras }\end{array}$ & $\begin{array}{l}\text { Front Hazard } \\
\text { Cameras }\end{array}$ & $\begin{array}{l}\text { Rear Hazard } \\
\text { Cameras }\end{array}$ \\
\hline Location & top of mast & top of mast & front bumper & rear bumper \\
\hline Height above ground, $\mathrm{cm}$ & 150 & 150 & 38 & 38 \\
\hline Stereo baseline, $\mathrm{cm}$ & 25 & 10 & 10 & 10 \\
\hline Color method & three-chip $C C D^{a}$ & $\mathrm{~B} \& W$ & B\&W & $\mathrm{B} \& \mathrm{~W}$ \\
\hline Field of view, deg & $8 \times 11$ & $25 \times 33$ & $25 \times 33$ & $25 \times 33$ \\
\hline Pixel resolution, mrad & 0.3 & 1 & 1 & 1 \\
\hline Image size, pixels & $480 \times 640$ & $480 \times 640$ & $480 \times 640$ & $480 \times 640$ \\
\hline $\begin{array}{l}\text { Data volume } \\
\text { uncompressed, Mbits }\end{array}$ & $\begin{array}{l}\text { 7.37 Mbits } \\
\text { (color) }\end{array}$ & 2.45 Mbits & 2.45 Mbits & 2.45 Mbits \\
\hline
\end{tabular}

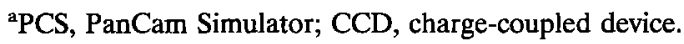

ments to the site in a variety of formats, as well as control access privileges. Postdoc proved to be especially useful because it is accessible from any platform using the World Wide Web and did not require special computer skills. The use of Postdoc facilitated keeping the large distributed science team involved in the mission throughout its duration.

\subsection{Mission Methodology and Groundrules}

One week prior to the mission start, the simulated Descent Images were provided to the science team to help them plan the mission. Figure 3 shows two of the simulated descent images. While the science team had previously been provided data with orbital resolution, only descent images have sufficient resolution to allow planning a rover traverse. The descent images also allowed the science team to understand where they had landed within the context of the orbital images they had previously seen. They were also used to make preliminary geologic maps of the region, and several such maps were developed by different team members prior to the start of rover operations [see De Hon et al., this issue].

The science mission started February 8, 1999, with a few hours of training and orientation about mission operations. Flight rules and constraints were defined. The "allowed" data volume in a command cycle was $40 \mathrm{Mbits}$, based on that planned for the 2001 lander mission, and commands were to be designed to return this. Images could be compressed using JPEG compression and/or by reducing spatial resolution using pixel averaging. Rover observation targets were to be selected with the expectation that the rover would not be able to move more than $10 \mathrm{~m}$ in a single daily command cycle. In planning requests, the science team was asked to specify a list of operations to perform and to specify the priority of each operation in case all operations could not be done. The science team was allowed to designate samples to be collected. A Marsokhod arm placement and image of the designated target with the arm camera were used as proxies for sample collection by the rover. The actual sample was collected by a field team member. Thus the science team was allowed to designate samples for

Table 5. Near Infrared Spectrometer Characteristics

\begin{tabular}{ll}
\hline \multicolumn{1}{c}{ Characteristic } & \multicolumn{1}{c}{ Description } \\
\hline Wavelength range, $\mu \mathrm{m}$ & $0.35-2.5$ \\
Spectral resolution, $\mu \mathrm{m}$ & 0.001 \\
IFOV & $1^{\circ}(\sim 17$ mrad $)$ aligned with left \\
& PCS imager \\
Data volume & $\sim 35 \mathrm{~Kb}$ per spectrum \\
Operation mode & involvement of field assistant \\
\hline
\end{tabular}

collection without their size being a constraint and without the time penalty associated with rover collection of samples. Some additional samples were collected by the field team that were used to help determine the accuracy of remote-sensing observations.

\subsection{Summary of Rover Mission}

This section summarizes the rover mission (phases 1-2) part of the field test. Figure 3 shows descent image views of the landing site area and shows rover stops $1-3$. Table 8 provides a detailed daily summary of the data acquired for reference with the narrative below. Table 9 is a brief summary of key elements of the rover mission.

The mission began with the acquisition of a full-color stereo PCS panorama of the landing site (Figure 3, Site 1), at a resolution of $1 \mathrm{mrad} / \mathrm{pixel}$, comparable to the resolution of the IMP camera on Pathfinder [Smith et al., 1999]. Plate 2 shows the panorama. For convenient identification of objects the science team nicknamed features in the descent and panoramic imaging. Nomenclature was based primarily on the movie "Star Wars," and names referred to in the text are shown in Plate 2. The PCS camera was capable of $0.3 \mathrm{mrad} / \mathrm{pixel}$ resolution, but lower-resolution images could be acquired by pixel averaging on board the rover. This was necessary to limit the data volume of large panoramic products. However, prior to mission start, an "insurance panorama" was acquired at full resolution and stored in the field for later transmission if bandwidth was available. Six hundred images from this panorama were ultimately transmitted. Also provided to the science team at the start of mission operations was a TIR spectral cube of size $8 \times 15$ pixels in the direction of an object dubbed "White Rock" by the science team (Figure 3 and Plate 2). These data provided the science team with a complete view of the landing site area with which to plan the mission.

At Site 1 the science team requested full-resolution PCS images and VNIR and TIR spectra of targets selected from the landing site mosaic (Plate 2) as well as designated the first sample (nicknamed Valentine on the basis of its color and shape) for collection. These data were downlinked on February 9 . Using these data, the team constructed a morphological and spectral classification of the rocks in the area. One of the targets selected for spectroscopy was a light colored rock with a small chip in the surface exposing a subsurface that appeared light green in color. The exobiology team suggested that the green area might be a biomarker for endolithic microorganisms and requested VNIR spectra to look for the spectral signature of chlorophyll. This request was uplinked along with the collection of the sample "Valentine." 


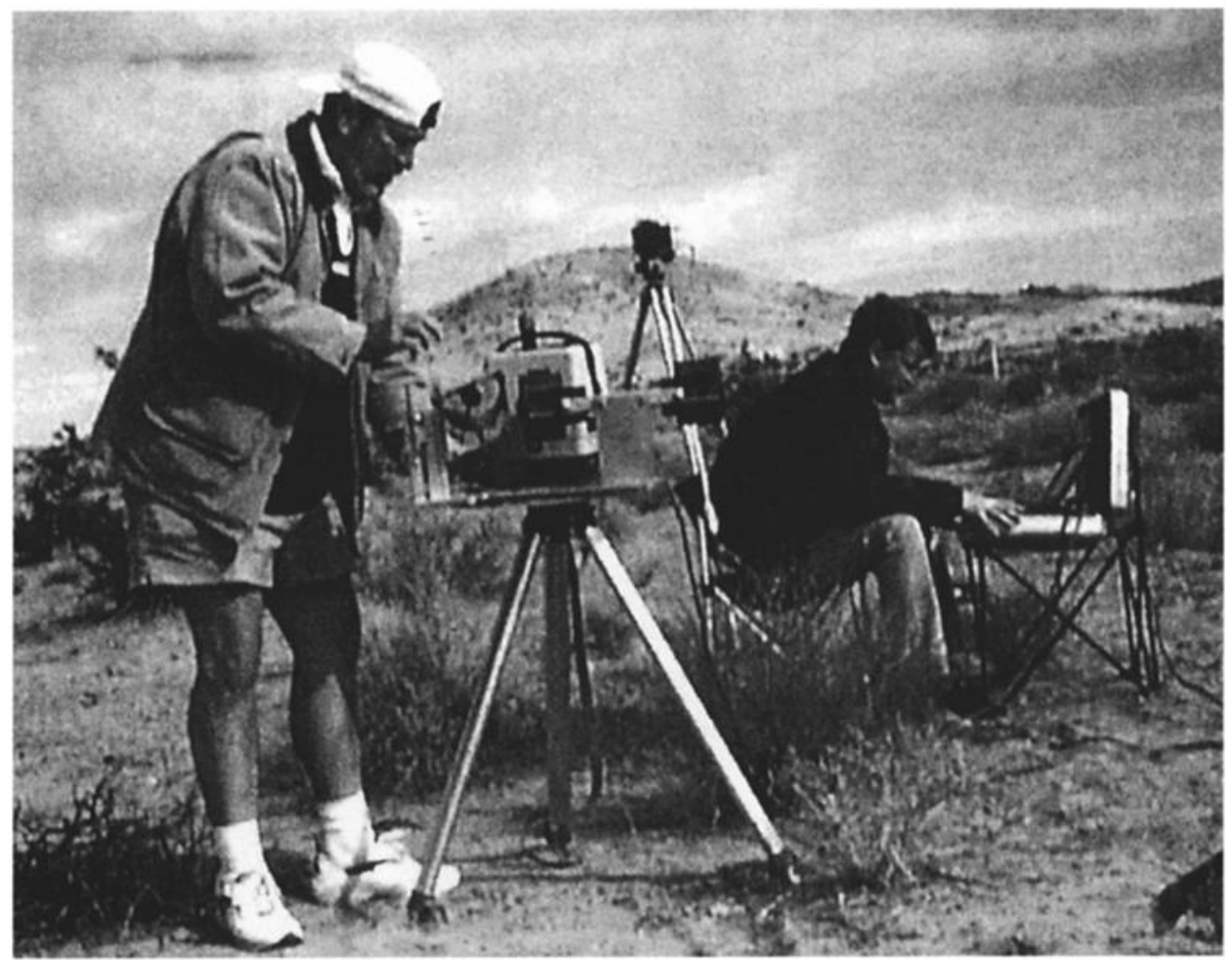

Figure 4. The thermal infrared spectrometer mounted on a tripod. The instrument was pointed by a field assistant (shown standing). Instrument functions and data collection are controlled by a laptop computer (operator seated).

Next, the rover drove $10 \mathrm{~m}$ west from the landing site to Site 2. The uplink commands associated with the drive included acquisition of color PCS images directly in front of the rover to prepare for additional spectral and/or sample collection at the next uplink opportunity. Following the move, on February 10, a navigation panorama and a PCS panorama quadrant in the direction moved were also acquired. The motivation for the move to Site 2 was that the science team desired samples of outcrops visible in the hills above the landing site (see Plate 2, e.g., Acorn Hill, White Rock, Bobba Fett Peak). However, the team initially underestimated the difficulty of reaching even the closest outcrop (White Rock) during the mission simulation. Once this was realized, the team reasoned that they could instead characterize the outcrops using spectroscopy and collect spectrally similar samples from among the near-field rocks of the alluvium. Thus the team next focused on spectral characterization of hills above the landing site and targets near the landing site, acquiring both point spectra and spectral cubes. Additional support imaging was acquired to prepare for another sample acquisition and for the next drive.

On February 13 the sample "Emperor" was collected. The rover then drove $30 \mathrm{~m}$ to Site 3, a small arroyo east of the

Table 6. Thermal Emission Spectrometer Characteristics

\begin{tabular}{ll}
\hline \multicolumn{1}{c}{ Characteristic } & \multicolumn{1}{c}{ Description } \\
\hline Wavelength range, $\mu \mathrm{m}$ & $8-14$ \\
Spectral resolution, $\mathrm{cm}^{-1}$ & 6 \\
NE $\Delta \mathrm{T}, \mathrm{K}$ & $0.07-0.20$ \\
IFOV & $15 \mathrm{mrad}\left(0.86^{\circ}\right)$ \\
Data volume & $\sim 1 \mathrm{~Kb}$ per calibrated spectrum \\
Operation mode & human-operated field instrument \\
\hline
\end{tabular}

landing site (see Figure 3b). By this time the methodology of first acquiring images before making decisions on spectral targets was recognized as too inefficient because of the short time period between data downlink and the next command uplink period. Thus the uplink command required the rover to drive to Site 3 as well as perform imaging and spectroscopy of the near-field surface before and after disturbing the surface with the rover wheels. The actual spot for performing this "scuff test" was chosen blindly with the expectation that much of the material in the arroyo would be similar. Ground-truth samples were collected of the arroyo materials before and after the scuff test. A full-resolution PCS partial panorama was acquired that provided for a geomorphological assessment of arroyo materials.

The rover was next transported to Site 4 by the field team on February 15 (4 in Figure 1). The move to Site 4 accommodated the science team's desire to study the paleoshorelines. However, we note that a rover traverse of the distance between Sites 3 and $4(\sim 0.5 \mathrm{~km})$ would have been unrealistic in less than a few months of actual mission time. The method of

Table 7. Robotic Arm Camera

\begin{tabular}{ll}
\hline \multicolumn{1}{c}{ Characteristic } & \multicolumn{1}{c}{ Description } \\
\hline Color method & Illumination with colored LEDs \\
Field of view, degrees & $50 \times 26$ \\
Image size, pixels & $512 \times 256$ \\
Effective resolution, mrad/pixel & 0.94 (close), 1.85 (far) \\
Exposure control & $0-32 \mathrm{~s}$ in $5 \mathrm{~ms}$ steps \\
Focus control & $11 \mathrm{~mm}$ to infinity \\
Resolution at closest focus, $\mu \mathrm{m}$ & 23 \\
Data volume uncompressed, Mbits & 1.6 \\
\hline
\end{tabular}




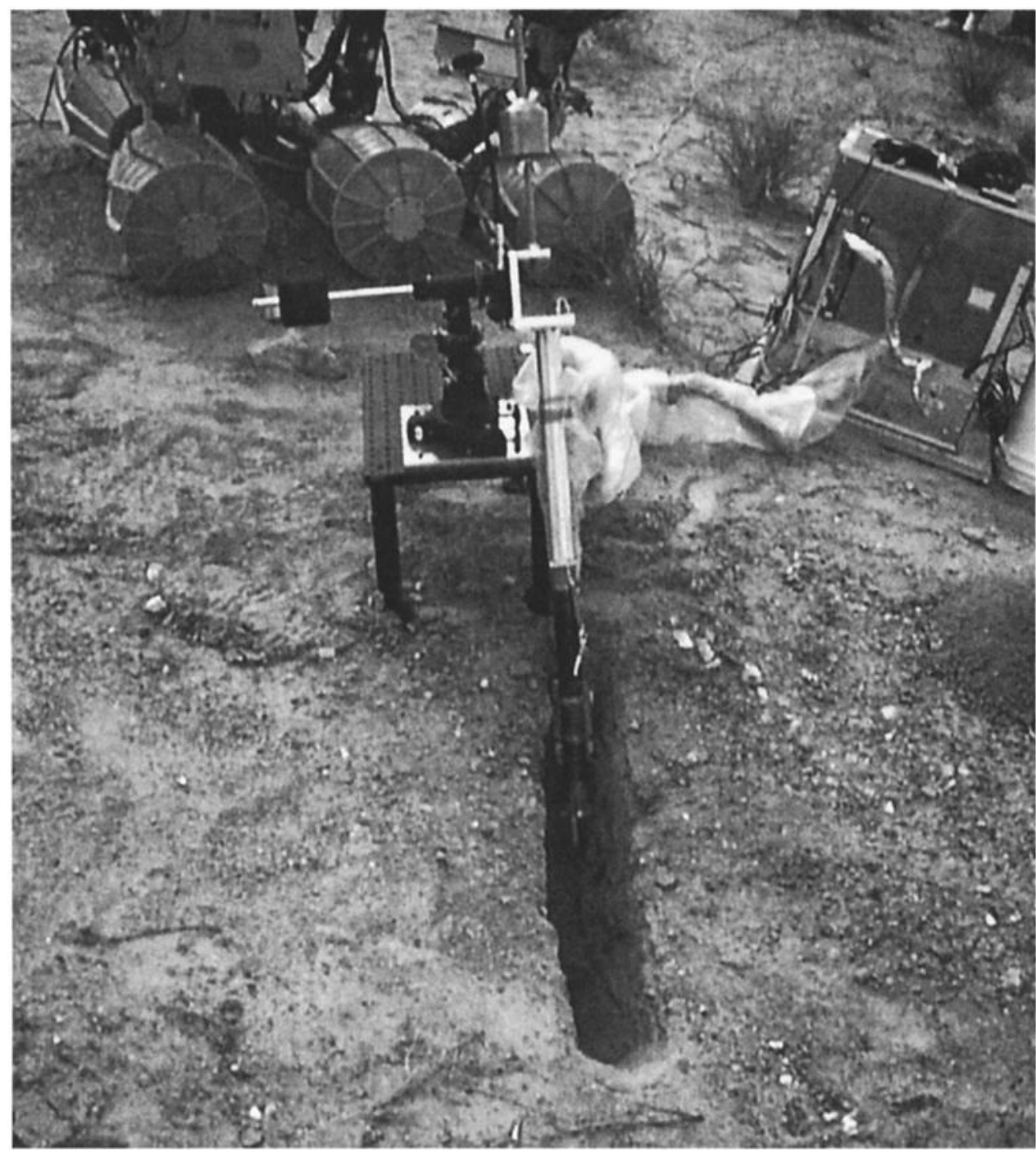

Figure 5. Robotic Arm Camera (RAC) imaging the walls of a trench. The RAC model is mounted on a tripod and positioned by an operator in the field. The control electronics are mounted in the equipment rack on the right side behind the tripod. Marsokhod is behind the RAC tripod bench.

obtaining images and spectra "blindly" upon arriving at a new location was again used at Site 4 . Here VNIR spectral image cubes were acquired to the left and right of the rover location, along with a PCS pan of the arm workspace to prepare for sample collection. In the next command (February 16) a rover sample was collected from directly below the arm. Then, a small trench was dug by a field assistant, and a ground-truth sample was collected from the trench bottom. PCS images and TIR and VNIR spectra were also collected of the trench to help characterize trench materials. The final rover operation was to drive $50 \mathrm{~m}$ east (into the sunset), taking random images along the way.

Table 10 summarizes the samples collected and the remote science team's characterization of the samples (column 2, Table 10). Following the mission, the samples were sent to an analytical laboratory (Spectrum Petrographics, Inc.) for thin section preparation, petrographic analysis, and photomicrography. This analysis is summarized in column 3 of Table 10. Table 2 of Johnson et al. [this issue] has the detailed results of the laboratory analysis.

\subsection{Summary of RAC Mission Simulation}

The last 2 days of the mission simulation (February 19-20) focused on simulating key aspects of the Mars Surveyor 2001 lander mission, specifically the mission components of digging a trench into the subsurface and analyzing the trench and exhumed material using RAC imaging, PanCam imaging, and TIR spectroscopy. The experiment is described in detail by Yingst et al. [this issue]. Specific objectives were to (1) demonstrate/test the ability of the RAC to define soil structure and clast size in a substrate of unknown qualities and (2) test the synergistic interpretation of data sets from instruments selected for the 2001 lander, including descent imaging, RAC imaging, PanCam imaging, and Mini-TES spectrascopy, to produce a holistic understanding of the site. These mission elements followed up on the objective that the science team was trying to achieve at Site 4 (examining the subsurface) but using a trenching and imaging system designed for this purpose.

For this experiment segment the Marsokhod, the RAC, and the TIR spectrometer were set up at Site 5 (see Figure 1), a site 


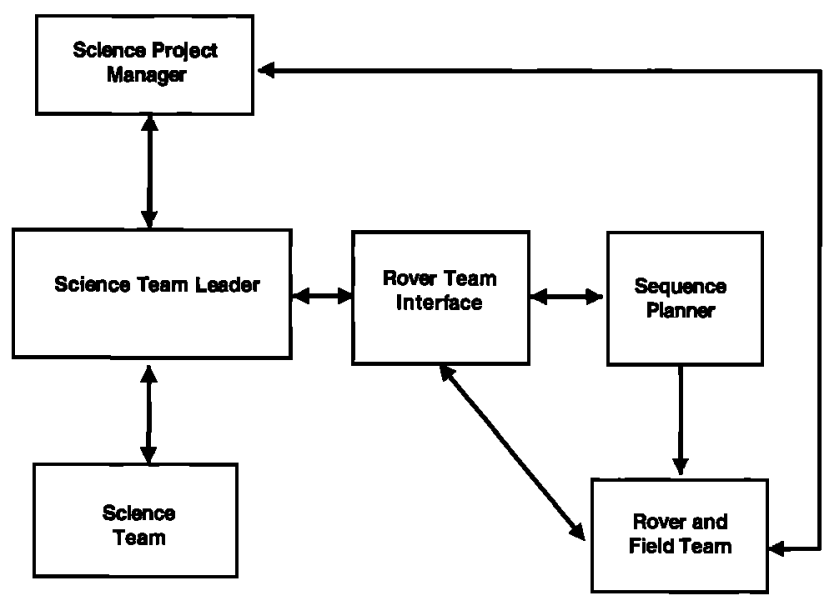

Figure 6. Organization and communication flow for the science mission. The mission activities were coordinated by a Mission Manager. The science team was led by a Team Leader who communicated science requests to the Rover Team Interface. The Rover Team Interface worked with the Sequence Planner to implement the request into a command to the rover and also communicated with the field team about requests for data from instruments that required human operation.

with subsurface layering chosen to evaluate the ability of the science team to identify and analyze these layers. A new science team, associated with the RAC instrument, came to mission control to direct this phase of the experiment. This team had not participated in the rover mission and therefore were working only from data acquired at Site 5 . The experiment began with acquisition of a horizon panorama obtained with the RAC. PCS images and RAC images were obtained of the work envelope of the arm. The science team used the data to select locations within the arm work envelope for digging the trench and depositing the tailings. A $1 \mathrm{~m}$ long by $15 \mathrm{~cm}$ wide trench was dug radial to the arm work envelope by a field assistant with a trowel.

The data sequence began by obtaining RAC and PCS imaging and TIR spectra of the area where the trench would be dug and tailings would be deposited. Then, $10 \mathrm{~cm}$ depth of material was excavated at the trench site and put on the tailings pile, which was then imaged with the RAC, and a PCS image and a TIR spectra image were taken. At the end of each digging sequence the walls of the trench were imaged with the RAC. Data were acquired for the tailings and trench for each $10 \mathrm{~cm}$ increment until the entire $50 \mathrm{~cm}$ depth was achieved. Figure 7 shows a mosaic of the RAC images of the trench after completion.

Samples were collected from each vertical level in the trench and imaged with the RAC in microscope mode. This was possible in the field (in principal) but was not accomplished because strong winds at the field site blew the grains out of the RAC scoop. Plate 3 shows a microsopic image of the fines. Table 11 summarizes the data obtained during the RAC experiment.

\section{Remote Science Interpretations}

This section presents a summary of the interpretations of each discipline team and an assessment of their accuracy.

\subsection{Geomorphology Team}

The conclusions of the geomorphology team are discussed by $D e$ Hon et al. [this issue] and summarized here. The team determined that carbonates are the oldest materials and consist of coarsely crystalline dolomite and lesser calcite, interstratified by quartz-rich sediments. Conical knobs northeast and southwest of the landing site were interpreted to be quartz-rich sedimentary rocks that might be silicic igneous or hydrothermal materials. Dark tones in the descent images were interpreted to be mafic materials and most likely intrusive mafics, although basalts or amphibolites were also considered to be possible. Resistant dark material capping the surface north-northeast of the playa was interpreted to be relatively young basalt. Banded materials of Sites 4 and 5 were interpreted to be paleoshorelines of an extended lake. The playa itself was interpreted to be actively recharged in the present epoch. The inferred geologic history, based on the stratigraphy, was that the earliest recorded event was the deposition of carbonate sediments in warm shallow seas, interstratified with quartz-rich sediments. These sediments were buried and metamorphosed. Extensional tectonism and erosion then exhumed these materials, and normal faulting created mountain blocks and intermountain closed basins. Erosion generated an alluvial apron that blanketed the lower slopes of the mountains and basin floor. Erosion of the highlands and deposition of alluvium in channels on these fans are intermittent and ongoing but less active than in the past. Extensional tectonism remains active. Channels emptying out of the higher regions onto the floor of the basin supplied water that ponded in the closed basin to form a lake with a shoreline at considerably higher levels than present. The lake highstand represents a climate regime wetter and cooler than at present. Continued fan growth partially buried much of this earlier shoreline. Mafic volcanism occurred in association with extensional tectonism prior to playa lake development. The playa continues to fill with water intermittently in the arid climate of the present day. Basalt north of the playa, alluvial fan material, and playa material are probably Pliestocene in age. The highstand of the lake probably formed during Wisconsin glaciation.

Many of the interpretations of the nature of the geology in the field test area compared well with the results from the field geologist [Grin et al., this issue]. The playa lake and its paleoshorelines were correctly identified. The light colored rocks in the alluvium and light colored outcrops in the hills west of the landing site were correctly interpreted to be dolomitic and calcitic marbles. Skarn mineralization was also suggested to be associated with some of the marbles. The reddish rocks seen at Site 1 and the pale gray terrains in the eastern portion of this area were correctly identified as granitic rocks. The dark colored rocks and dark colored terrain and outcrops throughout the region were interpreted to be rocks of mafic composition. Alluvial aprons with different bulk compositions and ages were correctly interpreted.

The principal errors in interpretation were the following. First, the dark rocks were thought to be shallow intrusive basalts (incorrect) rather than amphibolites (correct). Second, dark rocks on the west side of the highland west of the landing site and to the north of the playa were considered to be basalts, when, in fact, they were dioritic rocks and amphibolites, respectively. Third, rocks with red colors on the TIMS image (Plate 1) were a variety of quartz-bearing rocks, including quartzofeldspathic gneiss, granitic rocks, and quartz-rich veins, 


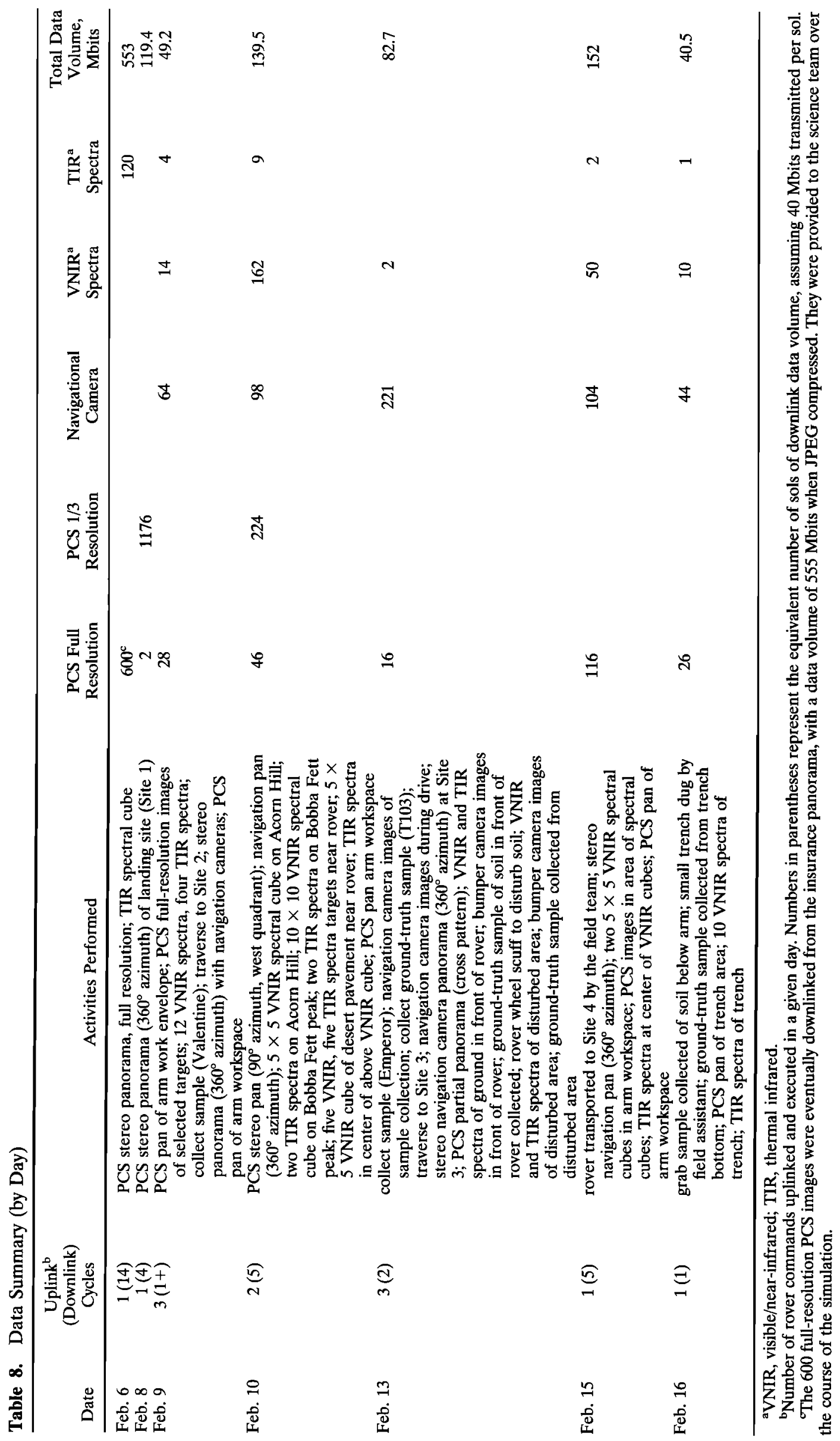


Table 9. Rover Mission Highlights Summary

\begin{tabular}{lc}
\hline \multicolumn{1}{c}{ Characteristic } & Description \\
\hline Number of sites visited by the rover & 4 \\
Distance traversed by the rover, $m$ & 90 \\
Number of images & \\
PCS & 2234 \\
Navigation & 531 \\
Arm & 6 \\
Number of spectra & 238 \\
$\quad$ VNIR & 138 \\
TIR & 1.14 \\
Total data volume delivered to science team, Gbits &
\end{tabular}

whereas they were interpreted to be mostly quartz-rich sedimentary rocks. Quartz-rich veins and granitic rocks were possible alternatives, although considered to be less likely. Finally, the interpretation that the landing site was on alluvial fans was not entirely correct, as the alluvium formed a thin veneer atop a pediment.

The erroneous interpretations resulted from the differences in the detail of information available from the rover compared to what one can obtain doing typical field geology. Distinguishing between a basalt and an amphibolite on the basis of imagery requires the ability to resolve light and dark colored minerals that are $\sim 1 \mathrm{~mm}$ in length or less. Most of the dark colored rocks in the close-up high-resolution rover imagery appeared to be homogeneously dark colored. These same rocks had the salt and pepper and sometimes foliated appearance of amphibolites viewed with the unaided eye while standing at the "landing site."

The mistaken impression that the dark rocks to the west of the carbonate highlands were tilted basalts overlying the carbonates was due to the lack of a clear understanding of the contact relationships between the carbonates and the dark rocks gained from the Descent, SPOT, and TIMS imagery. Examination of these images gave the impression that the dark rocks may form a veneer with an underlying contact that dipped at about the same angle as the topography. However, close examination of the rocks and observation of the contact relationships between the light and dark rocks in the field indicated that these rocks are mostly hornblende-biotite metadiorites and that they formed a tabular dike that dipped more steeply than the topography. The interpretation that the dark colored regions in the northern part of the field area were basalts came from the mistaken impression that they were relatively flat lying, when indeed they were just the pediment surface exposing the amphibolitic basement.

The inability to clearly distinguish the large variety of rocks that appeared red in the TIMS image resulted strictly from the fact that this image gave rocks with quartz contents ranging from about 10 to $100 \%$ a red color, which members of the geomorphology team did not understand. Finally, the thinness of the alluvial aprons on the pediments was easy to distinguish by a field geologist. By walking the arroyos, one could clearly see that bedrock outcrops are scattered down the base of arroyos more than a kilometer from the top of the pediment. Only one such outcrop was readily seen in the descent imagery.

Recommendations for future remote geology missions that could mitigate these problems of geological identification are the following. First, a strategy where high-resolution images of areas a few centimeters across are obtained on a few important

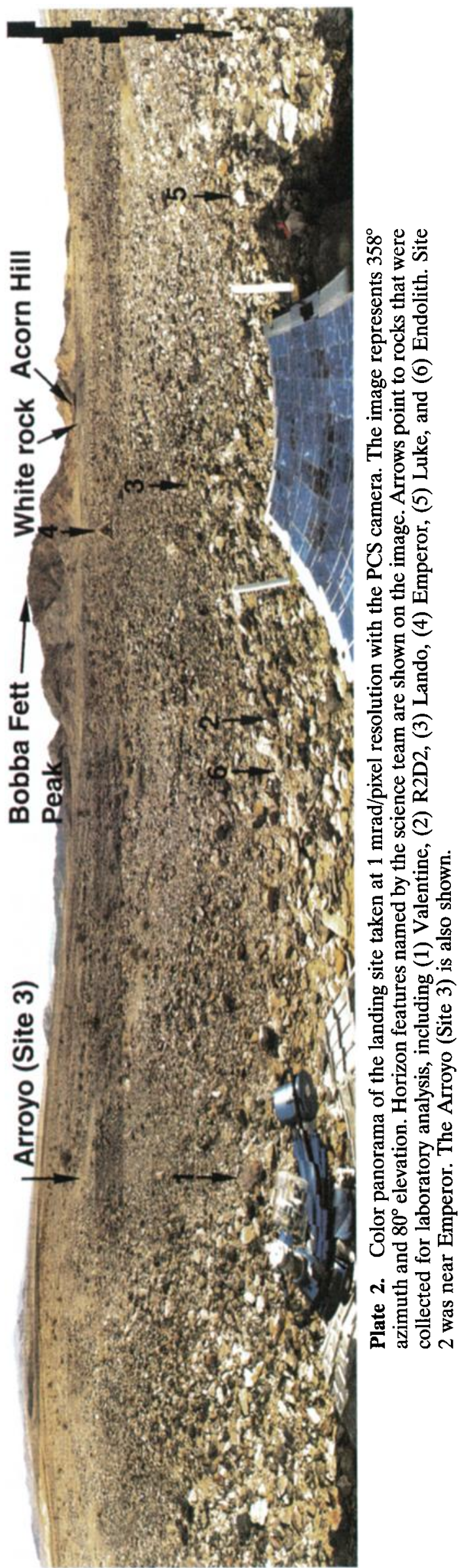


Table 10. Summary and Comparison of Field and Laboratory Analyses

\begin{tabular}{|c|c|c|}
\hline Sample & Interpretation From Remote Data & Petrology ${ }^{\mathrm{a}}$ \\
\hline Valentine & desert varnish coated silicic (granitic or sandstone) rock & $\begin{array}{l}\text { altered monzonite } \\
43 \% \text { k-spar } \\
40 \% \text { plagioclase } \\
8 \% \text { quartz } \\
4 \% \text { biotite }\end{array}$ \\
\hline Tubular & weathered basalt with serpentine & $\begin{array}{l}\text { altered metadiorite schist } \\
40 \% \text { plagioclase } \\
37 \% \text { actinolite } \\
10 \% \text { bio } \\
5 \% \text { quartz }\end{array}$ \\
\hline T103 & weathered basalt with serpentine & $\begin{array}{l}\text { altered diorite } \\
27 \% \text { plagioclase } \\
27 \% \text { amphibole } \\
27 \% \text { epidote } \\
10 \% \text { clays }\end{array}$ \\
\hline R2D2 & serpentine/lizardite plagioclase, serpentine, dolomite & $\begin{array}{l}\text { calc-silicate } \\
68 \% \text { calcite } \\
10 \% \text { dolomite } \\
10 \% \text { olivine } \\
5 \% \text { serpentine }\end{array}$ \\
\hline Lando & dolomite & $\begin{array}{l}\text { altered calc-silicate } \\
90 \% \text { dolomite } \\
5 \% \text { chlorite }\end{array}$ \\
\hline Emperor & dolomite + clays, some organics & $\begin{array}{l}\text { altered calc-silicate } \\
80 \% \text { dolomite } \\
10 \% \text { calcite } \\
10 \% \text { olivine }\end{array}$ \\
\hline Luke & dolomite + clays, some organics & $\begin{array}{l}\text { altered calc-silicate } \\
66 \% \text { dolomite } \\
15 \% \text { calcite } \\
15 \% \text { serpentine }\end{array}$ \\
\hline Endolith/exfoliated & dolomite + clays, some organics, chlorophyll & $\begin{array}{l}\text { altered calc-silicate } \\
91 \% \text { dolomite } \\
5 \% \text { olivine }\end{array}$ \\
\hline Arroyo, undisturbed & dolomite, quartz, feldspar & dolomite, plagioclase, $\mathbf{k}$-feldspar, epidote \\
\hline Arroyo, disturbed & clays + other weathering products, weathered silicates & $\begin{array}{l}33 \% \text { clay } \\
20 \% \text { plagioclase } \\
15 \% \text { quartz } \\
15 \% \text { calcite } \\
5 \% \text { dolomite } \\
5 \% \text { k-spar }\end{array}$ \\
\hline $\begin{array}{l}\text { Paleoshoreline, undisturbed } \\
\text { Paleoshoreline, disturbed }\end{array}$ & $\begin{array}{l}\text { quartz, feldspar, clay } \\
\text { clays + weathered silicates }\end{array}$ & $\begin{array}{l}\text { quartz, feldspar, carbonate cement } \\
28 \% \text { k-spar } \\
22 \% \text { plagioclase } \\
20 \% \text { clay } \\
15 \% \text { quartz } \\
15 \% \text { calcite }\end{array}$ \\
\hline Boba Fett, left & calcite & $\begin{array}{l}\text { calc-silicate } \\
81 \% \text { calcite } \\
10 \% \text { phlogopite }\end{array}$ \\
\hline Boba Fett, right & dolomite & $\begin{array}{l}\text { calc-silicate } \\
83 \% \text { dolomite } \\
8 \% \text { olivine } \\
5 \% \text { calcite }\end{array}$ \\
\hline
\end{tabular}

a"Clays" includes hydrous-alumino-silicates such as dickite, hectorite, kaolinite, montmorillonite, Fe-smectite, halloysite, and illite.

rocks after examining imagery like that collected during the Marsokhod field test could supply important information about the texture and mineralogy of the rocks but not add significantly to the data budget. Second, high-resolution digital elevation maps and detailed infrared and optical imagery may have allowed the geomorphology team to identify the dike-like nature of the dark colored rocks in the western part of the field area and the bedrock outcrops in the arroyos. Third, the range of mineralogy allowed by infrared spectra for rocks or regions needs to be clearly understood, which could be facilitated by better interaction between the geomorphology and mineralogy teams.

\subsection{Mineralogy Team}

The conclusions of the mineralogy team are discussed in detail by Johnson et al. [this issue]. In combination with the orbital multispectral data, descent imaging, and color rover imaging, the spectral measurements gathered by the VNIR and TIR field spectrometers helped to improve the science team's understanding of the local and regional lithology, geomorphology, and geology at each rover location and at the field site in general. The use of VNIR and TIR spectroscopy added considerable fidelity and confidence to the interpretations from the geomorphology team. The landing site was a good "grab 


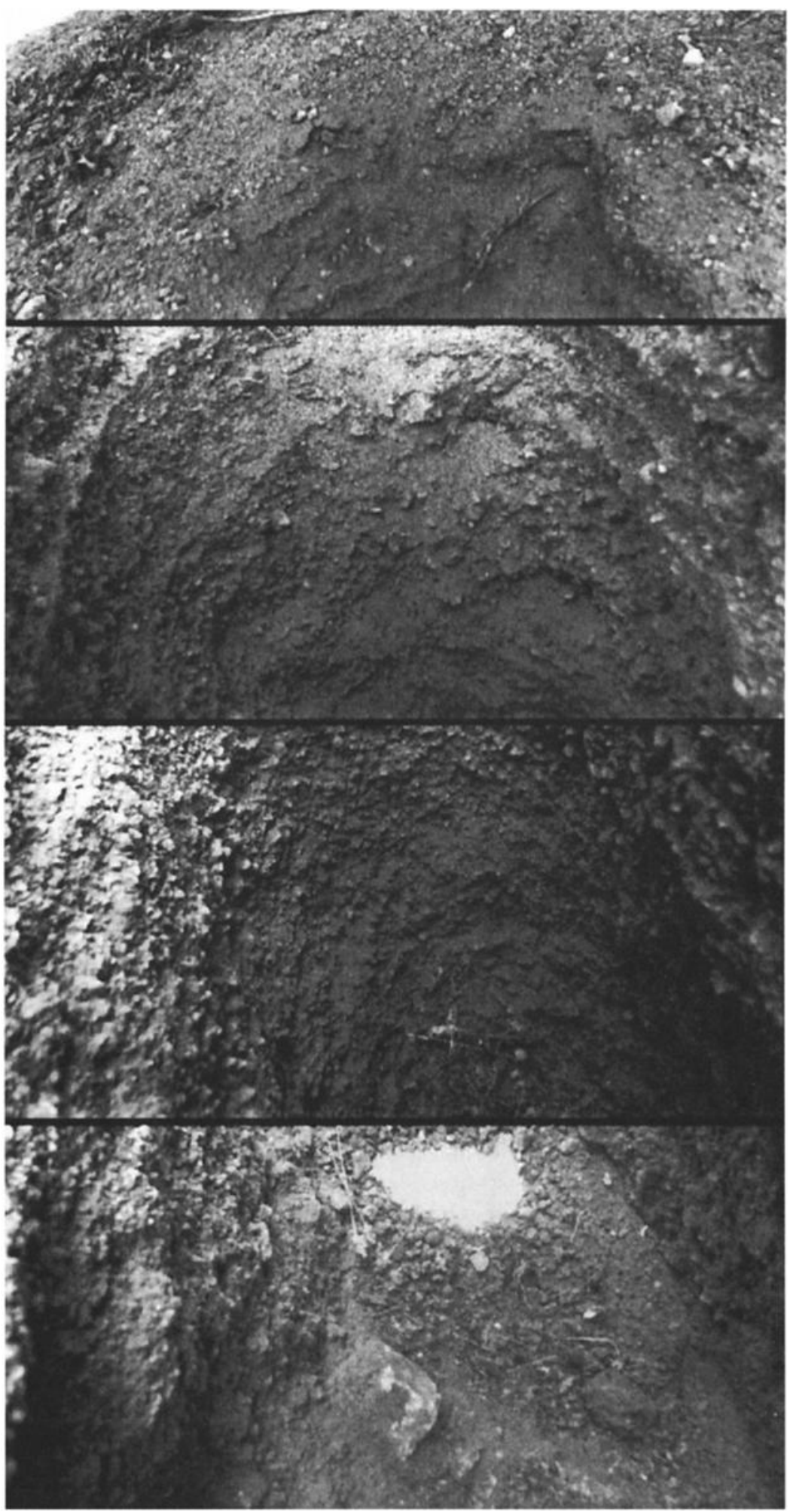

Figure 7. Mosaic of four RAC images of the walls of the $50 \mathrm{~cm}$ deep trench. Individual layers can be clearly seen. The top of the trench is at the top, and the floor is at the bottom.

bag" site, with a wide variety of lithologies and compositions within easy reach of the rover. The use of spectroscopy allowed identification of mineralogies associated with the local alluvial float rocks, which were then correlated to nearby source rocks using orbital and airborne mutlispectral and monochrome data, thereby minimizing the need to visit such distant outcrops for direct sampling. Without the ability to correlate these rocks with their source regions, the overall understanding of the geology and stratigraphy of the field site (including regions outside the traverse path of the rover) would have been considerably lessened. The complementary capabilities of having both VNIR and TIR spectra were demonstrated to improve 


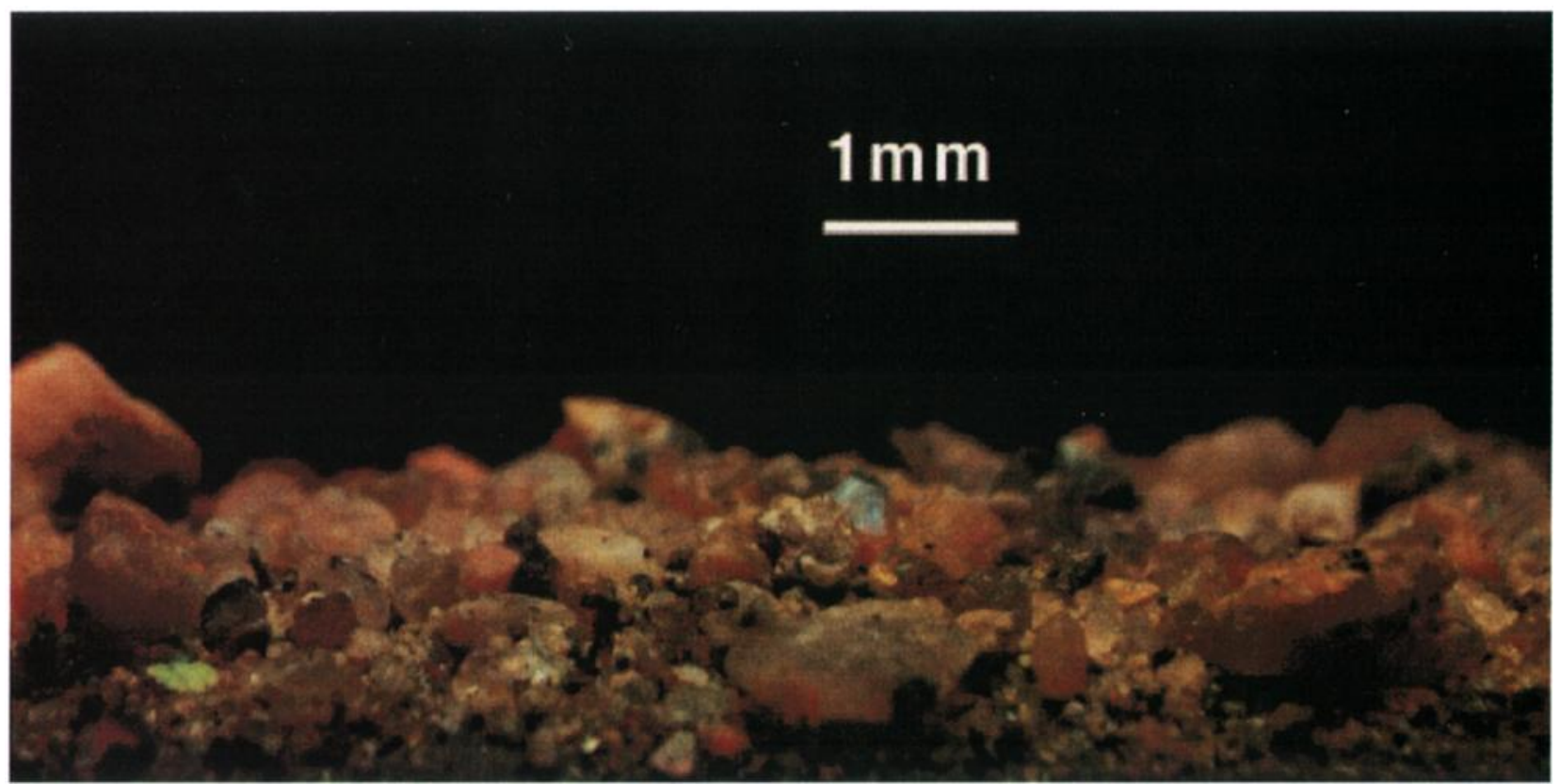

Plate 3. Image of fine-grained soils excavated from the trench at $10 \mathrm{~cm}$ depth. This image taken by the RAC in microscope mode is in focus at $10-11 \mathrm{~mm}$.

the ability to characterize a broad range of mineralogies. Spectra from both instruments independently exhibited spectral features indicative of carbonates, mafic rocks and associated weathering products, and silicic rocks with desert varnish-like coatings. The VNIR spectrometer also detected organic compounds such as chlorophyll from endolithic organisms. Comparison of undistubed and disturbed soils and gravels showed variations related to differences in composition and particle size.

The use of the spectroscopy allowed the positive identification of carbonate minerals at the site and even allowed different kinds of carbonate to be distinguished from each other (dolomite versus calcite). Five separate spectral classes of rocks were identified on the basis of the field spectra alone: (1) desert varnish coated silicic rocks, (2) weathered mafic rocks, (3) weathered mafic, serpentine-rich rocks, (4) dolomitic carbonate rocks, and (5) carbonates with clays and/or organics.

Field spectrascopic characterizations were compared with laboratory petrologic and spectral analyses of the returned samples (see Table 10; for complete details, see Johnson et al. [this issue]). Rocks identified as carbonates on the basis of field spectra alone all agreed very well with laboratory data, and all were petrographically categorized as calc-silicates (Lando, Luke, Emperor, Endolith/exfoliated), including the spectra of the Boba Fett Hills obtained on the horizon. Further, discrimination between dolomite and calcite made on the basis of field spectra for these samples was also confirmed by petrographic and laboratory spectral analyses. The arroyo and paleoshoreline field interpretations agreed moderately well with the petrologic analyses (laboratory spectra were not obtained for these samples). The results were better for the undisturbed than the disturbed samples. One reason for this difference is likely related to the reduced spectral contrast in disturbed soils due to fine-grained coatings, which makes deconvolution of spectral components more uncertain [Ramsey and Christensen, 1998]. Moderate to poor agreements between field interpretations and laboratory analyses were found for Valentine, Tubular, T103, and particularly R2D2. Valentine, indeed, exhibited a coated surface overlying a silicate-rich rock, but one that was an altered monzonite and not a granite or sandstone, as hypothesized from field spectra. Tubular and T103 were metadiorites, which is somewhat consistent with the interpretation of "weathered mafic" rocks with amphibole and/or a weathered basalt, although both rocks did not contain any serpentine minerals, as suggested from field spectra. The field spectra interpretation of R2D2 as a weathered mafic rock was incorrect for this calc-silicate sample, although serpentine minerals suggested by the field data were found during petrologic anal-

Table 11. Data Acquired During RAC Experiment ${ }^{\text {a }}$

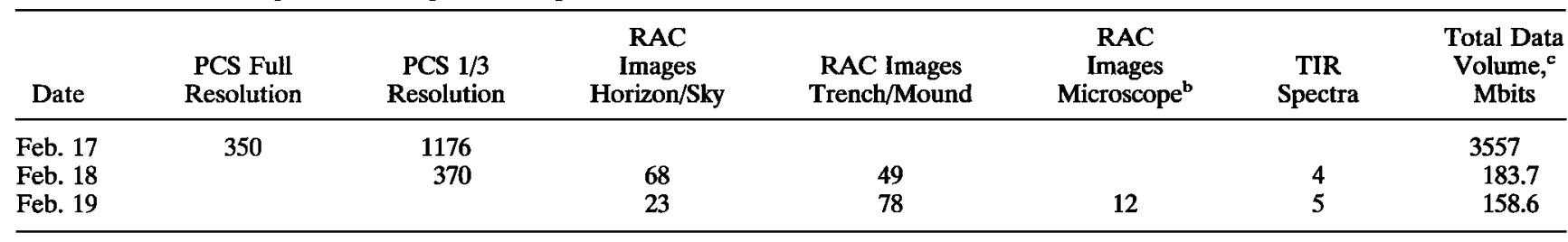

${ }^{a}$ RAC, Robotic Arm Camera; TIR, Thermal Infrared.

bMicroscope images were acquired after the field experiment because of high winds blowing the fines out of the scoop.

'Data volume with no data compression applied. 
ysis, as were small amounts of dolomite suggested by the TIR field spectra. However, in this case the rock sampled by the field team was not the dark rock identified as R2D2 by the off-site team on the basis of PCS images. The preconception that R2D2 was a dark rock biased interpretation of the VNIR spectra, whereas the TIR spectra lacked significant spectral features and were difficult to interpret. This underscores the need for color imaging in addition to spectroscopic data and further underscores the need to remain open to alternative interpretations.

One reason for the poorer identifications of Valentine, Tubular, T103, and R2D2 may result from the effects of discontinuous coatings, particularly on Valentine and R2D2. Deconvolution results from laboratory TIR spectra also show poorer correlation to the petrologic analyses, particularly for R2D2, which may imply that the coatings were thick enough to obscure the underlying mineralogy (i.e., greater than $\sim 100 \mathrm{mi}-$ crons) [Christensen and Harrison, 1993]. Alternatively, the deconvolution algorithm's effectiveness could have been compromised by low spectral contrast and perhaps the finegrained nature of the sample surface [Ramsey and Christensen, 1998]. Further, the surfaces measured for field and TIR lab spectra were natural (weathered), whereas petrologic analyses were based on thin sections of the rock interiors. These two methods measure quite different materials for these rock types. The lack of such coatings on the calc-silicate rocks allowed better identification of their true mineralogies.

In summary, these interpretations are generally correct, given the samples collected and analyzed. However, the presence of metamorphic rocks (marble, schist, amphibolite, altered monzonite) was not given equal consideration as igneous or sedimentary lithologies by the remote science team. This was likely due to an experimental bias influenced by the view that igneous and sedimentary regions dominate on Mars and other terrestrial planets. This serves as an important lesson from the field experiment. All of the incorrect interpretations from the field test would have been changed by the data from the returned samples, underscoring the value of sample return from Mars.

\subsection{Exobiology Team}

The exobiology team's conclusions are discussed in detail by Newsom et al. [this issue]. The team attempted to select samples for return with possible exobiology interest. Criteria for selecting interesting samples were developed, including (1) rocks with veins that could be due to hydrothermal activity, (2) rocks with visible fossil-like forms, (3) evidence of possible surficial life forms on rocks (such as lichen), and (4) evidence for possible endolithic lifeforms (in the form of greenish coloring near rock surface fractures) that could be related to subsurface layers. On the basis of these criteria, two target rocks were identified. One was a light colored rock that appeared to have a green tinge associated with the edge of a surficial layer, as if a piece of the layer had broken off, revealing the green material underneath (Plate 4). The other was a weathered carbonate sample with a significant amount of surface texture, suggesting possible presence of fossils. Subsequently, a VNIR spectrum was requested of the first rock at the position of the greenish deposit. However, the field team substituted a proxy sample with a similar green layer because they could not find either of the requested samples. Chlorophyll bands were readily identified in this spectrum, and the sample was requested for return. TIR spectra of the rock indicated that it was a dolomitic sample, common in the field area.

Following the rover test, the returned rock sample was broken apart, and in the laboratory VNIR spectra were measured of internal rock surfaces that exhibited green coloration that could be due to endolithic organisms. The spectra contain a band centered at $680 \mathrm{~nm}$ due to chlorophyll. This band is present in the spectra of the endolithic layer, the fresh rock surface, and the exposed rock surface, suggesting that phototrophic organisms are ubiquitous in the rock.

Microorganisms in the rock were studied and identified using light microscopy and epiflourescence microscopy. The subsurface layer of the rock is inhabited by coccoid Chroococcidioposis cyanobacteria; a small portion of the rock is also inhabited by a surface lichen. The genus of cyanobacteria is a typical member of many cryptoendolithic communities and is found occupying a similar niche in Antarctica [Nienow and Friedmann, 1993]. They inhabit pore spaces between rock grains in a habitat $2-5 \mathrm{~mm}$ below the surface of rocks where light levels are high enough for photosynthesis, but the depth buffers them against temperature extremes experienced in Antarctica (cold) and the Mojave (hot). The significance of these organisms in relation to Mars has been pointed out [McKay, 1993].

The biomarker recognized by the science team was common at the field site but could be seen only in a fracture zone of a light colored rock or by lifting many light colored rocks and observing the area where they contact the soil horizon. The identification required (1) images of rocks at sufficient resolution, i.e., comparable to the human eye, to identify subtle detail; (2) accurate color representation; (3) appropriately trained scientists who recognized the importance of the images and requested additonal data (spectra); and (4) perhaps a little luck; that is, this green layer was exposed because the surface layer of the rock had been spalled off by field operations at the landing site. It is plausible that rover operations or the impact of a lander could result in a similar fortuitous occurrence. Ideally, a rover should have capability equivalent to a geologist's rock hammer.

In spite of the success of this aspect of the experiment, there were many more examples of such endoliths in the field site that were missed by the science team. In fact, the rock Emperor, which was treated in a similar way to the "discovery" rock (it was imaged in color at highest resolution, field spectra were acquired of it, and it was designated as a return sample) also contained chasmolithic endoliths in a fracture visible at the surface, and this was missed entirely. A deep gully $100 \mathrm{~m}$ west of the landing site was not designated as a target by the science team. Had they gone there, they would have viewed exposed stratigraphy, including black organic-rich layers in its walls. Ostracode shells could be found in the paleoshoreline area (Sites 4-5), but none were recognized.

Still, this experiment demonstrates that it is entirely plausible that a sample of living organisms on Mars could be identified with the instrument complement used on this test. This adds considerable weight to the hypothesis that rover missions could contribute significantly to our understanding of life on Mars.

\subsection{RAC Team}

The results of the RAC field test are discussed in detail by Yingst et al. [this issue]. Combined with the results from the simulated Descent Imager and TIR spectrometer, the pan- 
oramic, stereo, and microscopic images taken by the RAC allowed identification of the overall mineralogy and geomorphology of the field site by the RAC science team. RAC microscopic images showed sufficient detail to identify the gross mineralogy of the site, as well as likely weathering processes at different depths within the trench, suggesting a local erosional sequence. The RAC panoramic images provided a local context to the mineralogic interpretations.

Grain color, luster, and cleavage were used to identify grains of quartz and feldspar, while a minority of dark grains were interpreted to represent a mafic component. TIR spectra indicate that the trench material is quartz-rich with clays but no detectable carbonate. Conglomerates of hydrous fine-grained minerals surrounding coarser-grained detritus were also identified at shallower levels $(10 \mathrm{~cm})$, suggesting that the majority of the soil is composed of resistant minerals, interspersed with less eroded minerals at the higher levels.

Analysis of grain morphology showed that rounded grains are prevalent at the deepest levels of the trench but are intermixed with angular grains closer to the surface. The size of rounded grains increases as a function of depth. At the deepest levels $(30-50 \mathrm{~cm})$ both pebbles and fines are very rounded, indicating fluvial deposit of these materials. Sand-sized grains were interpreted to be rounded owing to wave action at the lake shoreline. Less rounded grains appear above $10 \mathrm{~cm}$, indicating that the most recent history of the site was no longer dominated by fluvial transport. Surface pebbles are the most angular grains. Surface fines are rounded, although somewhat less than the deeper fines. These grains represent the most recent depositional layer possibly emplaced by runoff from the local massifs.

The general roundness of the smallest soil grains suggests that much of the fine-grained soil from the test site is composed of a diverse mix of quartz sand and feldspar grains with minor components of mafic material and other detritus deposited through alluvial flow and drier mass wasting from the surrounding massifs.

A saltation experiment, where the surface was repeatedly imaged during a period of high winds, showed minimal movement of fine grains, suggesting that the surface has a resistant layer such as duricrust that is formed by salts left behind by evaporation of water. The soil was thus interpreted to be composed of resistant quartz and feldspar, interspersed with less rounded, presumably more recently deposited grains of similar composition at shallower levels, ultimately capped by duricrust. There is no evidence for a well-developed lag deposit such as a desert pavement.

Using the RAC data in conjunction with descent imagery, the team was able to correctly infer some of the mineralogic diversity of the site, as well as its situation on an alluvial fan deposit. One surprising scientific result of the test is the lack of carbonates observed in the samples, despite the proximity of the test site to a carbonate-rich playa. Indeed, it was assumed that no carbonate grains were seen in the microscopic images because they were too small for RAC to reveal identifying mineralogic characteristics. The paucity of carbonates, however, was corroborated by data at TIR wavelengths retrieved from the site, demonstrating the importance of spectroscopic data as a complement to visual images. No petrographic analysis was performed on the samples collected at Site 5; however, the analysis from nearby Site 4 (Table 10, arroyo disturbed materials) indicates that carbonate and dolomite are both present in low to medium concentrations. They also were not recognized in the TIR spectra of Site 4 disturbed soils. As noted by the mineralogy team, spectra contrast in soils may be reduced owing to fine-grained coatings, which makes deconvolution of spectral components less accurate.

\section{Results and Recommendations for Future Rover Missions}

The purpose of rover mission simulations is to learn how to perform rover missions successfully. In this section, the results of this experiment, both successful and problematic aspects, are summarized and used to derive recommendations for improving the science return from rover missions. These recommendations are arranged from near to far term and range from operational approaches through technologies on the horizon to suggestions for engineering improvements and changes that affect mission design.

This experiment simulated the payload (MARDI, PanCam, Mini-TES, and RAC) and the experiment ground rules of a mission originally planned for 2001. The Athena payload [Squyres et al., 1999] was originally selected for flight on a long-distance sample collection rover to be flown in 2001. The MARDI, RAC, and Robotic Arm were selected for an accompanying lander payload. These payloads were later combined onto a stationary lander for 2001 , but that mission was canceled because of restructuring of the Mars program following the loss of the Mars Climate Orbiter and Polar Lander in 1999.

This experiment demonstrates conclusively that the payload and mission approach originally selected for 2001 is scientifically powerful even if it is stationary, but having even limited mobility allows a characterization of site diversity and investigation of site-specific hypotheses, as was demonstrated by rover observations at Sites $1-3$. Longer-range mobility would allow characterization of a variety of sites representing different geological processes, as illustrated by the move from the alluvial fan (Sites 1-3) to the paleoshorelines (Sites 4-5). The successful use of multiple types of data sets at a variety of spatial scales demonstrated their synergism. The science team made use of orbital imaging and thermal infrared data similar to that provided by the THEMIS instrument selected for the Surveyor 2001 orbiter, along with infrared spectrometers on the rover, rover mast cameras, and macroscopic and microscopic images from the RAC, to develop a more consistent and complete geologic picture than has been possible in past rover field experiments. The remote-sensing capabilities of infrared spectroscopy, combined with imaging, allowed distant features to be characterized and correlated with local rocks. Thus sample collection from the local area could be used to characterize major regional geologic units. Infrared spectroscopy was used to successfully distinguish between different lithologies not only near the rover but also at distances of hundreds of meters or more. The science team was able to distinguish subtle differences such as the geologic contact between dolomite and calcite at a distance of $0.5 \mathrm{~km}$. Also important was the ability to examine the subsurface by using the Robotic Arm capability to trench below the surface and the RAC to image trench walls and fines. Using this payload, the science team deduced consistent and largely correct interpretations. In a very short time (compared to the overall expected duration of a mission) the science team had understood in considerable detail the geology, mineralogy, stratigraphy, and exobiology of the site. The scientific productivity of this simulation strongly validates this payload and mission approach. 


\subsection{Recommendations for Mission Operations}

This experiment, and previous rover field tests, shows that performing science with a rover is sufficiently challenging, and missions are sufficiently short, that it is critical to use mission simulations to identify and test the capabilities needed to meet science objectives prior to the flight missions. Training both the science and operational teams on the mission configuration, and working out problems in a simulation environment, is very important and cost-effective when compared to the expense of sending the mission to Mars. Comparison with ground truth is an important way to train scientists to understand the limitations of instruments. Mission operations and science teams selected for flight should practice with their intended science payload and rover technical capabilities as closely simulated as possible before the actual mission commences. Achieving the science goals of the mission probably depends on this.

An important result of this field experiment was the successful incorporation of a distributed science team into mission operations. After just a few days of training, the science mission proceeded successfully and accommodated daily science mission planning even after the entire science team had returned to home institutions. Furthermore, the science team learned to produce written requests in sufficient detail that they could be understood and implemented correctly by the rover team. In most cases, science team members can work more effectively at their home institutions, where they have access to their own facilities. When missions last many months but must be planned daily, and science investigators come from institutions around the country and other parts of the world, travel and facility costs prohibit doing otherwise. The success of a distributed science team requires that they can easily access data and can share their analyses and ideas with other team members. Fortunately, the Internet now provides excellent capabilities.

A key result of this experiment was the successful identification of endolithic microbiota, a type of life form that could plausibly be found on Mars [see Newsom et al., this issue]. This is the first time that a discovery of this nature has been made in a mission simulation. The key difference between this and previous experiments may be the use of very high resolution color imaging. Three recommendations regarding imaging follow from this success and from mistakes in interpretation of imaging. First, achieving accurate interpretations often requires that the cameras perform as well as the human eye, which, in bright sunlight, can pick out features with an angular resolution of 0.15-0.2 mrad [Boff and Lincoln, 1988], as compared to $0.3 \mathrm{mrad} / \mathrm{pixel}$ for the $P C S$ and $0.9 \mathrm{mrad} / \mathrm{pixel}$ for the Pathfinder IMP camera [Smith et al., 1999]. Degrading resolution even slightly can lead to incorrect interpretations. However, the limitations set by mission data volume suggest that low spatial resolution images should be acquired for geologic context and that very small areas of target rocks should be imaged at much higher resolution than normal. Superresolution, a technique for obtaining improved resolution by combining repeated images of a target, was used for this purpose on Mars Pathfinder [Stoker et al., 1999]. Second, it is critical to present the images with accurate color rendering. For example, if the color balance of the image had been off slightly so that the subtle green color associated with the endolithic community was not recognized, this discovery would not have occurred. Third, high-resolution imaging should be accompanied by compositional information such as provided by infrared spectroscopy.

Science achievement is limited by the rate that rover operations proceed. Since the planned lifetimes of Surveyor Program missions are very limited (for example, 90 sols was the planned lifetime of the 2001 lander mission), it is critical to increase science efficiency. Here are some ways to optimize the efficiency of rover operations. Following landing or a move to a new area, a low-resolution panorama should be taken of the surroundings to help identify the main features of interest. Incorporating preliminary imaging and spectral measurements of near-field targets (i.e., within reach of a manipulator arm for sampling) as part of the uplink sequence of driving to a new rover location could save time by providing data with which to decide whether to sample in the next command. The ability to autonomously identify rocks or distinguish rocks from soils [Gulick et al., this issue] could be used to command point spectra of rocks with desired characteristics, which would allow more informed choices than "blind" measurements. The next priority is composition and texture of selected objects identified in the panorama. High-resolution, color images are needed, but the highest resolution can be confined to small areas to conserve data volume. Alternatively, spectra of a wide variety of targets could be acquired along with bore-sighted corresponding high-resolution imaging and the set could be analyzed with onboard spectral and image analysis routines [Gazis and Roush, this issue]. These results could be used to set downlink priority for returning the data. Once received on the ground, the images should be color processed and examined carefully before moving on.

One of the most difficult parts of operating a rover mission is the daily generation of commands. Software is needed to help rover operators more easily develop commands and to help scientists to better participate in mission planning. Command generation tools need to provide users with estimates of spacecraft resources and data volumes required by the command. Operator errors could be reduced with a high-fidelity simulation environment that would allow the operator to visualize the rover's performance of the command. Command generation tools using a virtual reality visualization environment were used in this field test [Blackmon et al., 1999]. An advanced simulation environment was developed for visualizing operations on the Mars Polar Lander [Stoker and Zbinden, 1999]. These are important steps, but further development and field testing are needed to produce a robust and easy to use command generation system.

\subsection{Recommendations for Future Rover Missions}

It is difficult to accurately position a rover, and this drives the slow pace of rover operations. With current navigation technology, accurate traversing of only a few meters is possible in a single command. For sampling targets, several command cycles are required to position the rover accurately. Before rovers can traverse kilometers over relatively unknown terrain, a requirement of future rover missions [COMPLEX, 1999], a much better navigation approach must be used. The performance of dead reckoning would be improved with turns or drives on a desired heading referenced against a directionsensing device. Continued research in visual tracking systems should also be pursued for short-range navigation and instrument placement. Point-to-point navigation over large distances would be enabled by an ability to accurately determine position in an absolute reference frame, made possible by the use of a 


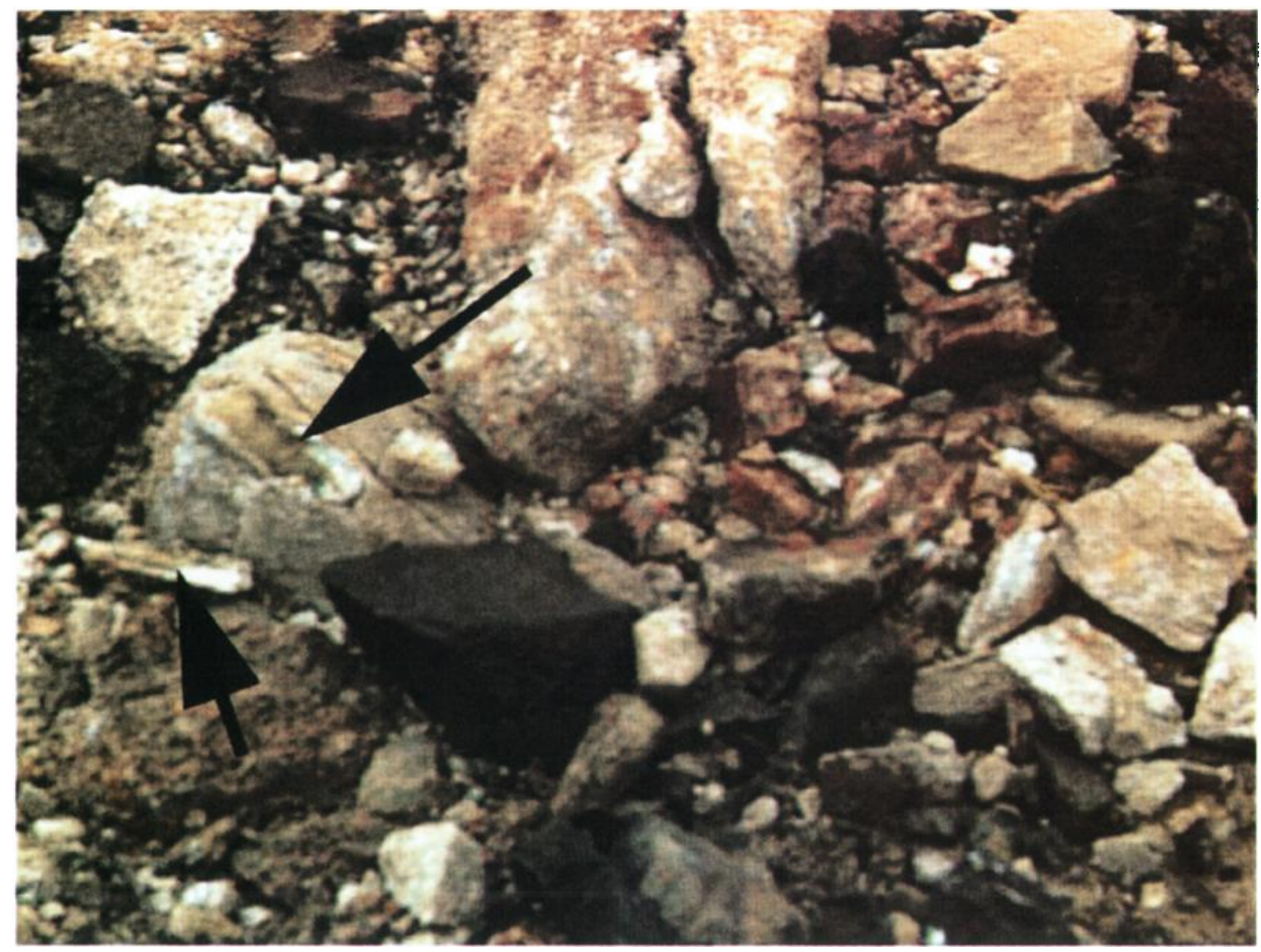

Plate 4. Discovery image of the rock containing endolithic microbes. Arrows point to the rock with a chip out of the surface (top arrow) and the chip lying below it (bottom arrow). The subsurface area exposed by the chip is greenish. The coloration is due to the presence of chlorophyll.

global positioning system (GPS). The high leverage factor on rover performance of having GPS may well justify the cost of implementing it on Mars. Greater mobility than occurred in this test has been demonstrated in previous tests that had more frequent command cycles [Stoker, 1998; Christian et al., 1997; Arvidson et al., 1998]. Mission architectures that allow multiple command cycles per Martian sol should be considered in the design of future missions.

Current generation entry systems, and the direct entry mission architecture adopted by the Surveyor program, lead to landing site targeting uncertainties that are very large compared to the range of expected mobility. Thus it is not possible to investigate specific targets chosen from orbital imaging. Landing sites must thus be chosen in a desirable regional area, with the expectation of traversing no more than a few hundred meters. Improvements in targeting accuracy should be a high priority because they will vastly reduce the risk of landing in rugged but interesting terrain and allow the rover to explore specific sites of interest.

Using solar power for rover missions provides severe constraints on performance. In addition, because of dust accumulation on the solar panels, rover lifetimes are expected to be only a few months. This is in contrast to the nuclear-powered Viking landers, which operated continuously for 7 Earth years on Mars. With Viking-style power supplies, even with the slow pace of operations, rovers could reasonably be able to perform traverses of tens of kilometers over a period of years. Even if using nuclear power is not feasible, technologies should be developed to remove dust from solar panels, and engineering systems should be designed for greater longivity.

Descent imaging provides the context for rover operations, but only the highest-resolution descent images are sufficient to plan rover traverses, and these cover only a small area. For example, a resolution of $10 \mathrm{~cm}$ is needed to plan a trafficable course for a rover with $20 \mathrm{~cm}$ wheel diameter. The current MARDI imager provides this resolution for an area only $100 \mathrm{~m}$ in size. In addition, topographic information is very important for planning traverses such as could be quickly derived from stereo imaging. Development of an alternative kind of aerial imaging platform, such as airplanes that can fly on Mars, would be very desirable for obtaining high-resolution aerial surveys that would facilitate planning a long-distance rover traverse.

Finally, it is important to recognize that many things are missed in a rover mission that would be observed by a scientist in the field. A variety of things were missed by the science team that were passed during traverses or even actually imaged and studied [see Grin et al., this issue]. For example, a lateral fracturing of the rock Emperor with green chasmo-endolithic material was not noticed by the remote science team. Desert varnish coated dark rocks were interpreted as being basaltic rocks, and amphibolites were interpreted as being as basaltic rocks as well. In the field, amphibolites were immediately recognized by geologists. While an example of a rock containing an endolith was recognized, the high proportion of rocks containing such evidence was not recognized, including that in the collected rock Emperor. Fossil biological material was not 
identified, such as Pleistocene ostracod shell debris and organic layering apparent in the walls of the gullies. Numerous desert animals that inhabited the field site were observed by the field team but not by the rover. Thus, while mobile science payloads can accomplish good geological field science, they are far inferior to field scientists on Mars.

\section{Conclusions}

The most important conclusions of this field test follow:

1. The payload and mission approach selected for the 2001 mission are scientifically powerful and should be flown. It would contribute substantially to achieving the goals of the Mars Surveyor Program.

2. Mission simulations are an important and cost effective way to ensure successful and scientifically productive rover missions.

3. A distributed science team, located at their home institutes, can effectively operate a rover mission over a long period of time.

4. Imaging with the performance of the human eye is needed for accurate geological interpretations. Human foveal resolution is needed for imaging in selected areas, supported by lower-resolution context imaging. Accurate color representation is also needed.

5. Infrared spectrascopy, combined with imaging, is important for determining mineralogy and provides a remote-sensing capability that can substitute for increased mobility.

6. Rover mobility is limited to no more than a few meters per command cycle. Increasing rover operational range will require at least one of, and possibly all of, the following: improved onboard navigation technology, more frequent commanding, use of an absolute positioning system (GPS), and longer-lived missions.

Acknowledgments. The success of this test relied on the contribution of many people, to whom we would like to express gratitude. Special thanks to Ray Arvidson, who provided considerable help and advice in organizing the test, selected the field site, provided the orbital data sets used in the test, and georeferenced the descent images. Paul Lucy provided the thermal infrared spectrometer instrument used in the test. Special thanks go to the field team (Hans Thomas, Anne Wright, Linda Kobayashi, Cesar Mina, Edmund Grin, Jeff Moersch, Ted Roush, and Keith Horton), who spent a month in the field in rough weather and maintained a brutal schedule to support this test. The Marsokhod rover team made this experiment possible. We would like to thank John Bresina, Richard Washington, Dave Miller, Maria Bualat, Sergei Sokolov, Gary Haith, Aaron Klien, Joel Hagen, and many others in the Automation and Robotics Area at NASA Ames for their incredible effort and dedication to this activity. We thank the NASA Advanced Technology Program under Dave Lavery for financial sponsorship of the activity.

\section{References}

Arvidson, R. E., et al., Rocky 7 prototype Mars rover field geology experiments, 1, Lavic Lake and Sunshine Volcanic Field, California, J. Geophys. Res., 103, 22,671-22,688, 1998.

Basilevski, A. T., W. J. Markiewicz, N. Thomas, and H. U. Keller, Morphologies of rocks within the rock garden at the Mars Pathfinder landing site, J. Geophys. Res., 104, 8617-8636, 1999.

Blackmon, T., C. Neveu, C. Allport, L. Nguyen, A. Kline, D. Smith, C.
Anderson, and V. Gupta, Command generation for planetary rovers using Virtual Reality, paper presented at 5th International Symposium on Artificial Intelligence, Robotics, and Automation in Space, Eur. Space Res. and Technol. Cent., Noordwijk, Netherlands, 1999.

Boff, K. R., and J. E. Lincoln (Eds.), Engineering Data Compendum: Human Perception and Performance, vol. 1, p. 202, Armstrong Aerosp. Medical Res. Lab., Wright-Patterson Air Force Base, Ohio, 1988.

Bresina, J., K. Golden, D. Smith, and R. Washington, Increased flexibility and robustness of Mars rovers, 5th International Symposium on Artificial Intelligence, Robotics, and Automation in Space, Eur. Space Res. and Technol. Cent., Noordwijk, Netherlands, 1999.

Bridges, N. T., R. Greeley, A. F. C. Haldemann, K. E. Herkenhoff, M. Kraft, T. J. Parker, and W. A. Ward, Ventifacts at the Pathfinder landing site, J. Geophys. Res., 104, 8595-8615, 1999.

Burchfield, B. C., and G. A. Davis, Mojave Desert and environs, in The Geotectonic Development of California, edited by W. G. Ernst, pp. 217-252, Prentice-Hall, Englewood Cliffs, N. J., 1981.

Cabrol, N. A., and E. A. Grin, Distribution, classification and ages of Martian impact crater lakes, Icarus, 142, 160-172, 1999.

Cabrol, N. A., et al., Nomad Rover Field Experiment, Atacama Desert, Chile, 1, Science results overview, J. Geophys. Res., this issue (a).

Cabrol, N. A., et al., Nomad Rover Field Experiment, Atacama Desert, Chile, 2, Identification of paleolife evidence using a robotic vehicle: Lessons and recommendations for a Mars sample return mission, J. Geophys. Res., this issue (b).

Chapman, M. G., and J. S. Kargel, Observations at the Mars Pathfinder landing site: Do they provide "unequivocal" evidence of catastrophic flooding?, J. Geophys. Res., 104, 8671-8678, 1999.

Christensen, P. R., and S. T. Harrison, Thermal infrared emission spectroscopy of natural surfaces: Application to desert varnish coatings on rocks, J. Geophys. Res., 98, 19,819-19,834, 1993.

Christian, D., D. Wettergreen, M. Bualat, K. Schwer, D. Tucker, and E. Zbinden, Field experiments with the Ames Marsokhod rover, in 1997 Field and Service Robotics Conference, pp. 93-100, Aust. Robotics and Auton. Assoc., Canberra, Australia, 1997.

Committee on Lunar and Planetary Exploration (COMPLEX), A scientific rationale for mobility in planetary environments, Space Studies Board, Natl. Res. Counc., Natl. Acad. Press, Washington, D. C., 1999.

Crowley, J. K., and S. J. Hook, Mapping playa evaporite minerals and associated sediments in Death Valley, California, with multispectral thermal infrared images, J. Geophys. Res., 101, 643-660, 1996.

De Hon, R., et al., Observation of the geology and geomorphology of the 1999 Marsokhod test site, J. Geophys. Res., this issue.

Gazis, P. R., and T. Roush, Autonomous identification of carbonates using near-IR reflectance spectra during the February 1999 Marsokhod field tests, J. Geophys. Res., this issue.

Gillespie, A. R., A. B. Kahle, and F. D. Palluconi, Mapping alluvial fans in Death Valley, California, using multichannel thermal infrared images, Geophys. Res. Lett., 11, 1153-1156, 1984.

Glazner, A. F., and J. A. Supplee, Migration of Tertiary volcanism in the southern United States and subduction of the Mendocino Fracture Zone, Earth Planet. Sci. Lett., 60, 426-436, 1982.

Golombek, M. P., A message from warmer times, Science, 283, 14701471, 1999.

Golombek, M. P., et al., Overview of the Mars Pathfinder Mission: Launch through landing surface operations, data sets, and science results, J. Geophys. Res., 104, 8523-8553, 1999.

Greeley, R., A. T. Basilevsky, R. O. Kuzmin, C. Stoker, and G. Taylor, Science results from the Marsokhod tests, Amboy lava field, California, 1994, paper presented at International Planetary Rover Symposium, Moscow, Russia, May 1994.

Greeley, R., M. Kraft, R. Sullivan, G. Wilson, N. Bridges, K. Herkenhoff, R. O. Kuzmin, M. Malin, and W. A. Ward, Aeolian features and processes at the Mars Pathfinder landing site, J. Geophys. Res., 104, 8573-8584, 1999.

Grin, E. A., and N. A. Cabrol, Limnologic analysis of Gusev crater paleolake, Mars, Icarus, 130, 461-474, 1997. 
Grin, E., M. K. Reagan, N. A. Cabrol, E. A. Bettis III, C. T. Foster Jr., C. R. Stoker, T. L. Roush, and J. E. Moersch, Geological analysis of the Silver Lake Marsokhod field test from ground-truth sampling and mapping, J. Geophys. Res., this issue.

Gulick, V. C., R. Morris, M. A. Ruzon, and T. Roush, Autonomous image analyses during the 1999 Marsokhod rover field test, J. Geophys. Res., this issue.

Hartmann, W. K., M. C. Malin, A. S. McEwen, M. H. Carr, L. Soderblom, P. Thomas, E. Danielson, P. James, and J. Veverka, Evidence for recent volcanism on Mars from crater counts, Nature, 397, 586$589,1999$.

Hook, S. J., and A. B. Kahle, The micro Fourier transform interferometer ( $\mu$ FTIR)-A new field spectrometer for acquisition of infrared data of natural surfaces, Remote Sens. Environ., 56, 172-181, 1996.

Horton, K. A., J. R. Johnson, and P. G. Lucey, Infrared measurements of pristine and disturbed soils, 2, Environmental effects and field data reduction, Remote Sens. Envrion., 64, 47-52, 1998.

Jakosky, B. M., Water, climate, and life, Science, 283, 648-649, 1999.

Johnson, J. R., et al., Geological characterization of remote field sites using visible and infrared spectroscopy: Results from the 1999 Marsokhod field test, J. Geophys. Res., this issue.

Kahle, A. B., and A. F. H. Goetz, Mineralogic information from a new airborne Thermal Infrared Multispectral Scanner, Science, 222, 2427, 1983.

Keller, H. U., et al., The MVACS Robotic Arm Camera, J. Geophys. Res., in press, 2001.

Korb, A. R., P. Dybwad, W. Wadsworth, and J. W. Salisbury, Portable FTIR spectroradiometer for field measurements of radiance and emissivity, Appl. Opt., 35, 1679-1692, 1996.

Malin, M. C., and M. H. Carr, Groundwater formation of Martian valleys, Nature, 397, 589-591, 1999.

Malin, M. C., G. E. Danielson, A. P. Ingersoll, H. Masursky, J. Veverka, M. A. Ravine, and T. A. Soulanille, Mars Observer Camera, J. Geophys. Res., 97, 7699-7718, 1992.

Malin, M. C., et al., Early views of the Martian surface from the Mars Orbiter Camera of Mars Global Surveyor, Science, 279, 1681-1685, 1998.

McEwen, A. S., M. C. Malin, M. H. Carr, and W. K. Hartmann, Voluminous volcanism on early Mars revealed in Valles Marineris, Nature, 397, 584-586, 1999.

McKay, C. P., Exobiological significance of Antarctic microbial communities, in Antarctic Microbıology, edited by E. I. Friedmann, pp. 593-601, John Wiley, New York, 1993.

Moore, H. J., D. Bickler, J. Crisp, H. Eisen, J. Gensler, A. F. C. Haldemann, J. Marijevic, L. Reid, and F. Pavlics, Soil-like deposits observed by Sojourner, the Pathfinder rover, J. Geophys. Res., 104, 8729-8746, 1999.

Morris, R. V., et al., Analyses of Martian surface materials during the Mars Surveyor 2001 mission by the Athena Instrument payload, Proc. Lunar Planet. Sci. Conf. 29th, abstract, 1326, 1998.

Newsom, H. E., J. L. Bishop, C. Cockell, T. L. Roush, and J. R. Johnson, Search for life on Mars in surface samples: Lessons from the 1999 Marsokhod rover field experiment, J. Geophys. Res., this issue.

Nienow, J. A., and E. I. Friedmann, Terrestrial lithophytic (rock) communities, in Antarctic Microbiology, edited by E. I. Friedmann, pp. 343-412, John Wiley, New York, 1993.

Ore, H. T., and C. N. Waren, Late Pleistocene-early Holocene geomorphologic history of Lake Mojave, California, Geol. Soc. Am. Bull., 82, 2553-2562, 1971.

Ramsey, M. S., and P. R. Christensen, Mineral abundance determınation: Quantitative deconvolution of thermal emission spectra, $J$. Geophys. Res., 103, 577-596, 1998.

Rice, J. W., Jr., V. R. Baker, and D. H. Scott, Cascading lakes, spillways, and subaqueous debris flows: Models for Martian paleolakes, in The Fifth International Conference on Mars, abstract 6241, Lunar and Planet. Inst., Houston, Tex., 1999.

Rover Team, Characterization of the Martian surface deposits by the Mars Pathfinder rover, Sojourner, Science, 278, 1765-1768, 1997.

Sabine, C., V. J. Realmuto, and J. V. Taranik, Quantitative estimation of granitoid composition from thermal infrared multispectral scanner (TIMS) data, Desolation Wilderness, northern Sierra Nevada, California, J. Geophys. Res., 99, 4261-4271, 1994.

Scott, D. H., J. W. Rice Jr., and J. M. Dohm, Martian paleolakes and waterways: Exobiologic implications, Orig. Life Evol. Biosphere, 21, 189-198, 1991.

Scott, D. H., M. G. Chapman, J. W. Rice Jr., and J. M. Dohm, New evidence of lacustrine basins on Mars: Amazonis and Utopia Planitiae, Proc. Lunar Planet. Sci. Conf. 22nd, abstract 5362, 1992.

Scott, D. H., J. M. Dohm, and J. W. Rice Jr., Map showing channels and possible paleolake basins, U.S. Geol. Surv. Misc. Invest. Ser., Map I-2461, 1995.

Smith, D. E., et al., The global topography of Mars and implications for surface evolution, Science, 284, 1495-1503, 1999.

Smith, P. E., et al., Results from the Mars Pathfinder camera, Science, 278, 1758-1765, 1997.

Spencer, J. E., Late Cenozoic extensional and compressional tectonism in the southern and western Avawatz Mountains, southeastern California, Mem. Geol. Soc. Am., 176, 317-333, 1990.

Squyres, S. W., et al., The Mars 2001 Athena Precursor Experiment (APEX), Proc. Lunar Plan. Sci. Conf. 30th, abstract, 1672, 1999.

Stoker, C., The search for life on Mars: The role of rovers, J. Geophys. Res., 103, 28,557-28,575, 1998.

Stoker, C. R., and E. Zbinden, Virtual reality on Mars Pathfinder and Mars Polar Lander, paper presented at NATO Research and Technology Organization Symposium on Advanced Mission Management and System Integration for Improved Tactical Operations, Florence, Italy, Sept. 1999.

Stoker, C. R., E. Zbinden, T. T. Blackmon, B. Kanefsky, J. Hagen, P. Henning, C. Neveu, D. Rasmussen, K. Schwehr, and M. Sims, Analyzing Pathfinder data using virtual reality and super-resolved imaging, J. Geophys. Res., 104, 8889-8906, 1999.

Thomas, P. C., et al., Bright dunes on Mars, Nature, 397, 592-594, 1999.

Thomson, D. G., The Mojave Desert region, California: A geographic, geologic, and hydrologic reconnaissance, U.S. Geol. Surv. Water Supply Pap., 578, 159 pp., 1929.

Walker, J. D., and B. R. Wardlaw, Implications of Paleozoic rocks on the Soda Mountains, northeastern Mojave Desert, California, for late Paleozoic and Mesozoic Cordilleran orogenis, Geol. Soc. Am. Bull., 101, 1574-1583, 1989.

Ward, A. W., L. R. Gaddis, R. L. Kirk, L. A. Soderblom, K. L. Tanaka, M. P. Golombek, T. J. Parker, R. Greeley, and R. O. Kuzmin, General geology and geomorphology of the Mars Pathfinder landing site, J. Geophys. Res., 104, 8555-8572, 1999.

Wettergreen, D., H. Thomas, and M. Bualat, Initial results from vision-based control of the Ames Marsokhod rover, in IEEE International conference on Intelligent Robotics and Systems, Inst. of Electr. and Electron. Eng., Grenoble, France, Sept. 1997.

Yingst, R. A., P. H. Smith, M.T. Lemmon, R. L. Marcialis, J. W. Rice Jr., and J. D. Weinberg, DIRTCam in the desert: The Silver Lake field test of the Robotic Arm Camera, J. Geophys. Res., this issue.

J. Aubele and L. Crumpler, New Mexico Museum of Natural History and Science, Albuquerque, NM 87104.

J. Bishop, N. A. Cabrol, C. Cockell, E. Grin, V. Gulick, G. Hovde,

P. C. Lee, J. Marshall, T. R. Roush, J. Schreiner, M. Sims, C. R. Stoker, and H. J. Thomas, NASA Ames Research Center, Mail Stop 245-3, Moffett Field, CA 94035. (cstoker@mail.arc.nasa.gov)

N. Barlow, Department of Physics, University of Central Florida, Orlando, FL 32816.

E. A. Bettis III, T. Foster, and M. Reagan, Department of Geoscience, University of Iowa, Iowa City, IA 52242.

M. Chapman, J. R. Johnson, and K. Tanaka, U.S. Geological Survey, Flagstaff, AZ 86001.

S. Clifford, Lunar and Planetary Institute, Houston, TX 77058.

R. Craddock, Smithsonian Institution, Washington, DC 20560.

R. De Hon, Department of Geosciences, University of Louisiana, Monroe, LA 71209.

K. Horton, Hawaii Institute of Geophysics and Planetology, University of Hawaii at Manoa, Honolulu, HI 96822. 
M. T. Lemmon, J. W. Rice, P. H. Smith, and R. A. Yingst, Lunar and Planetary Laboratory, University of Arizona, Tucson, AZ 85721.

J. Moersch, Department of Geological Sciences, University of Tennessee, Knoxville, TN 37996.

H. E. Newsom, Department of Earth and Planetary Sciences, University of New Mexico, Albuquerque, NM 87131.

G. G. Ori, Dipartimento di Scienze, Universita' d'Annunzio, Viale Pindaro 42, 65127 Pescara, Italy.
S. W. Ruff, Department of Geology, Arizona State University, Tempe, AZ 85287

G. Thomas, Department of Industrial Engineering, University of Iowa, Iowa City, IA 52242.

(Received September 9, 1999; revised June 6, 2000; accepted June 28, 2000.) 